\title{
Modification of Vertical Earth Pressure Formulas for High Fill Cut-and-Cover Tunnels Using Experimental and Numerical Methods
}

\author{
Sheng Li $\mathbb{D}^{1},{ }^{1}$ Li Ma, ${ }^{2}$ I-Hsuan Ho $\mathbb{D}^{\circ},{ }^{3}$ Qicai Wang, ${ }^{1}$ Bentian Yu, ${ }^{1}$ and Peng Zhou ${ }^{1}$ \\ ${ }^{1}$ National and Provincial Joint Engineering Laboratory of Road \& Bridge Disaster Prevention and Control, \\ Lanzhou Jiaotong University, Lanzhou Gansu 730070, China \\ ${ }^{2}$ College of Civil Engineering, Lanzhou Institute of Technology, Lanzhou Gansu 730050, China \\ ${ }^{3}$ Harold Hamm School of Geology and Geological Engineering, University of North Dakota, 81 Cornell St. Stop. 8358, \\ Grand Forks, ND 58202, USA
}

Correspondence should be addressed to Sheng Li; ligwin@126.com and I-Hsuan Ho; ihsuan.ho@und.edu

Received 8 January 2019; Revised 1 May 2019; Accepted 17 June 2019; Published 18 July 2019

Academic Editor: Parviz Ghadimi

Copyright (c) 2019 Sheng Li et al. This is an open access article distributed under the Creative Commons Attribution License, which permits unrestricted use, distribution, and reproduction in any medium, provided the original work is properly cited.

\begin{abstract}
The high-filled cut-and-cover tunnel (HFCCT) is a solution to reclaim more useable lands due to the unique landforms of Loess Plateau in northwestern China. Because of the ultrahigh backfill, the estimation of vertical earth pressure will significantly affect the design and safety of the cut-and-cover tunnel (CCT). The current methods for estimating the vertical earth pressure are either to overestimate or underestimate the vertical earth pressure on the top of HFCCT. To more precisely estimate the vertical earth pressure distribution, the vertical earth pressure based on the soil column pressure, $\gamma h$ ( $h$ : the height of backfill above the CCT), needs to be properly modified. Considering different influential factors, four corresponding coefficients are proposed: $k_{0}$ : crosssectional shape of CCT effect, $k_{1}$ : stiffness of backfill effect, $k_{2}$ : width of CCT effect, and $k_{3}$ : coupling effect of slope angle, $\theta$, and the ratio of $\mathrm{B} / \mathrm{D}$. It is found that $k_{0}$ has little influence; the $k_{3}$ and $k_{1}$ reduce and $k_{2}$ amplifies the $\gamma h$. The corresponding general forms for these coefficients are determined based on finite element analysis results. A general equation for estimating vertical earth pressure for the HFCCT including these four coefficients is proposed. Meanwhile, this general form is verified by the numerical analysis results and experimental results for different cases. Therefore, this proposed equation is applicable to estimate the vertical earth pressure for existing or newly designed HFCCT. Furthermore, this proposed method can significantly reduce the computational work in engineering analysis.
\end{abstract}

\section{Introduction}

With the rapid development of economy and the massive constructions of high-speed railway, the demand of useable land has been increased tremendously in northwestern China. The Northwest Loess Plateau is mountainous and deep valley. In order to create more useable lands in this area, reclamation above cut-and-cover tunnel (CCT) is a good strategy. Due to these unique landforms in northwestern China, the required backfill above the CCT is usually massive and high. The high-filled (HF) materials will significantly increase the overburden pressure on this CCT. Therefore, to more accurately estimate the magnitude of the resulting increase in vertical earth pressure is necessary for the safety and operation of these existing CCTs. Additionally, the vertical pressure should be properly considered in the design when new high-filled cut-and-cover tunnels (HFCCT) are being built in this area.

For a newly designed HFCCT, undoubtedly, the CCT can avoid the curved design and ensure the safety of highspeed railway in operation. Moreover, compared to the conventional CCT, the required thickness of the lining structure and bearing capacity of foundation is greater. In addition, when the lining is made thicker, the concrete cracks due to shrinkage after hardening will also significantly affect the durability of the tunnel structure.

Currently, the available theories for estimating vertical earth pressure cannot be properly applied to these necessary 
high-filled backfills. The underestimation of the vertical earth pressure for this HFCCT may result in nonconservative designs in the bearing capacity of lining structure and foundation beneath the HFCCT. This would result in the failure of the lining structure and the excessive differential settlements of the foundation. These factors will significantly affect the safety and durability of the HFCCT. On the contrary, if the vertical earth pressure is overestimated, a relatively conservative design will be made and significantly increase the cost of the project. Accordingly, a better understanding of earth pressure distribution mechanisms enables the engineers to precisely estimate the vertical earth pressure around these underground structures and make the proper designs for HFCCT.

\section{Methods of Vertical Earth Pressure Estimation}

The analytical and experimental solutions for earth pressure on culvert were first proposed by Marston [1,2]. Later, it was determined that the loads on the underground structure are highly dependent on the relative movement between the central soil prism over the structure and the adjacent soil columns. Total vertical earth loads on the bottom slab of box culverts are sum of earth load on the top slab, frictional force on the sidewalls, and dead load of the structure $[3,4]$. Therefore, the vertical earth pressure, based on embankment installation (EI) culvert, is usually larger than $\gamma h(\gamma$ : unit weight of backfill $\left(\mathrm{kN} / \mathrm{m}^{3}\right), h$ : the height of backfill above the top of culvert $(\mathrm{m})$ ) [5-7]. The solution also shows that a greater difference between the actual vertical earth pressure and $\gamma h$ resulted when $h$ increases [8-14]. Conversely, another type of installation for culverts called trench installation (TI) results in a lower vertical earth pressure when compared to $\gamma h[7,14-20]$. Marston [2] found imperfect trench installation (ITI) based on this principles of mechanics, and engineers have developed this ITI method by means of adapting several types of compressible material over a buried pipe, such as leaves [21], baled straw [22], sawdust, woodchips [23, 24], or EPS ([25], Vaslestad and Johansen, 1993, [16, 17], Gu et al., 2005).

Currently, these analytical and experimental methods are widely used in practical engineering settings for estimating vertical earth pressure on the culverts with backfills and shallow pipe installations. Several specifications regarding vertical earth pressure estimation such as AASHTO [26], General Specifications for Design of Highway Bridges and Culverts [27], and Code for Design on Railway Bridges and Culvert [28] are based on Marston-Spangler (M-S) theory and empirical results. However, these methods mainly consider the vertical earth pressure on culverts or pipes having cross-sectional areas relatively small compared with HFCCTs. Furthermore, these methods lack proper considerations for the influences of slope angle of trench and the modulus of elasticity for the backfill materials. The estimation of the vertical earth pressure on the top of the CCT using the methods in the specifications of Code for Design of Road Tunnel [29] and Code for Design of Railway Tunnel

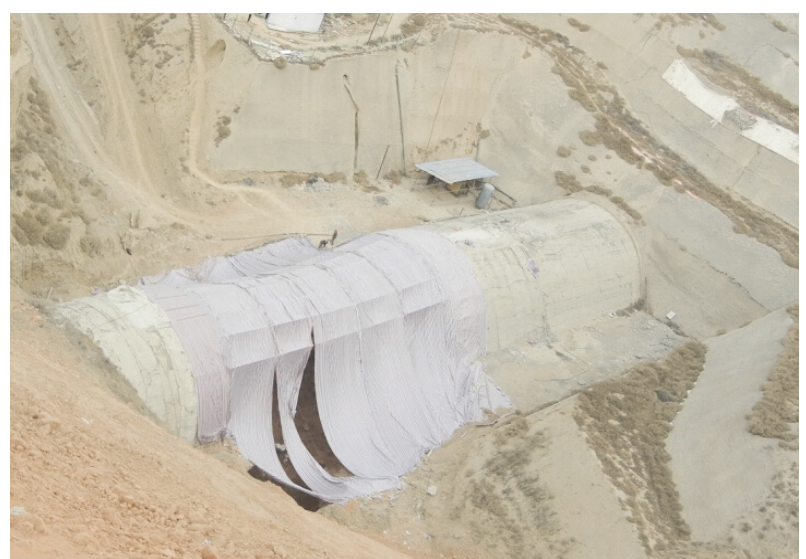

FIGURE 1: Changshoushan no. 2 cut-and-cover tunnel site.

[30] is based on the soil column pressure. These methods are applicable to these cases with the backfill heights which are smaller (usually between 2-4 meters). However, in the loading process of the HFCCTs, the computed magnitude of vertical earth pressure tends to be overestimated and underestimated with increasing backfill height. The loading mechanism and backfill-CCT interactions were not properly considered in these specifications.

In a recent HFCCT project on Yuli railway, which is between Chongqing and Lichuan in China, the vertical earth pressure was computed using a method which considers the effect of slopes adjacent to the backfill. The vertical earth pressure was found to be reduced and agreed with the soilheld function proposed by Luo and Zhang [31]. However, the width of bottom in the valley between two slopes in which the CCT is sitting and the characteristics of HF soils are not considered in the equation.

Practically, the slope angle of the valley, the width of the bottom of valleys where the HFCCT is sitting, the size of CCT, and the modulus of elasticity for backfill are found to have significant influence on the vertical earth pressure distribution on the top of HFCCT [32]. Accordingly, these factors need to be well taken account of when estimating the vertical earth pressure formula for HFCCTs. The objective of this paper is to further investigate these influential factors such as shape of CCT's cross-section, modulus of elasticity for backfill soil, the size of CCT's cross-section and the coupling of slope angle and the width of bottom of valleys where the HFCCT is sitting. Through the parametric study using finite element analysis, it has been determined that the soil column pressure, $\gamma h$, needs to be modified. Several coefficients corresponding to influential factors are proposed. A general formula for vertical earth pressure distribution on the top of HFCCT is recommended to satisfy the need for the HFCCT design.

\section{High-Filled Cut-and-Cover Tunnel}

The HFCCT includes the CCTs and massive backfills lying on top of those structures. Figure 1 shows a site of CCT called Changshoushan No. 2 in Gansu Province in Northwest 


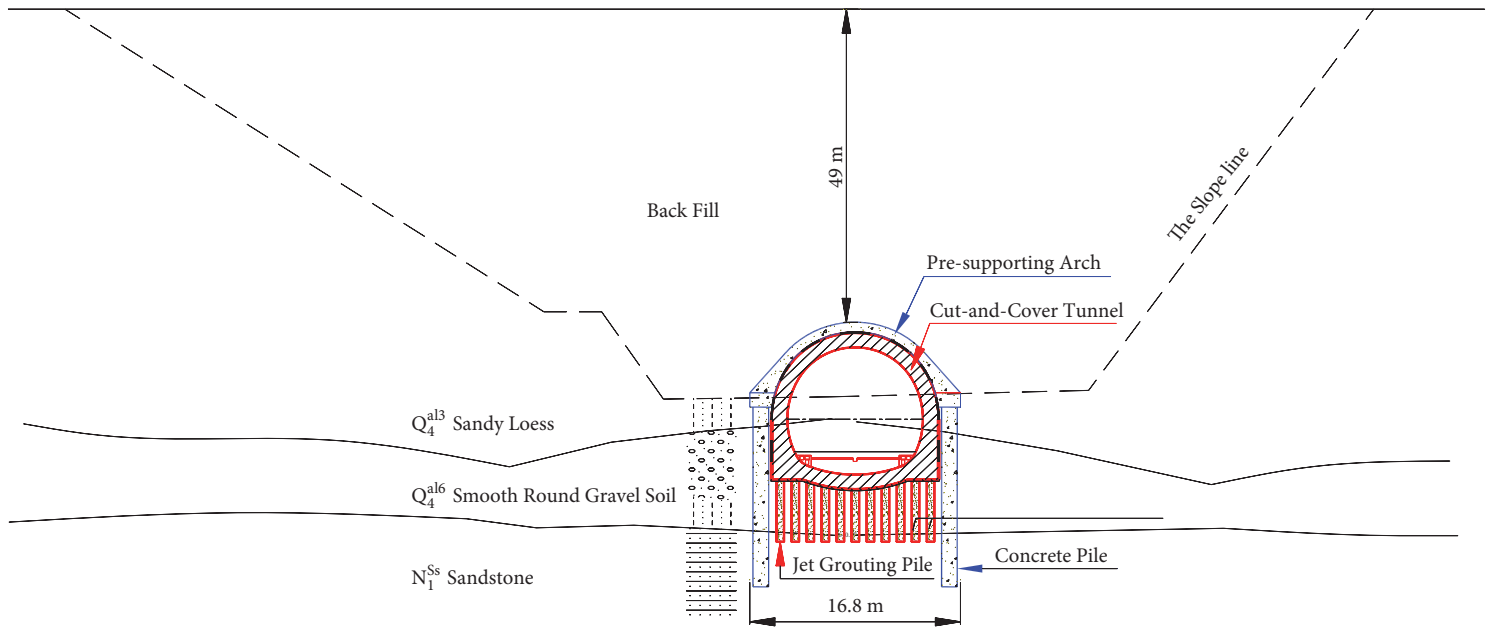

FIGURE 2: Cross-section of Changshoushan no. 2 HFCCT project.

TABLE 1: Physical property indexes of loess.

\begin{tabular}{|c|c|c|c|c|}
\hline Specific gravity & Natural & Optimum & Maximum & Plastic \\
\hline of soil grain & moisture content & moisture content & dry density & index \\
\hline $\mathrm{G}_{\mathrm{s}}$ & $\omega(\%)$ & $\mathrm{W}_{\mathrm{opt}}(\%)$ & $\gamma_{\mathrm{d}}\left(\mathrm{g} / \mathrm{cm}^{3}\right)$ & $\mathrm{I}_{\mathrm{p}}(\%)$ \\
\hline 2.69 & 4.33 & 15.25 & 1.925 & 9.47 \\
\hline
\end{tabular}

China. This CCT was built in valleys, and new land will be reclaimed for the use of Auto Expo garden. The cross-section of the CCT and the needed backfills are shown in Figure 2. A total of 49 meters of backfill is needed from the top of the CCT to the level of the new land (see Figure 2). The backfills are mainly composed of the borrowed loess from surrounding areas in Loess Plateau in western China. The soil is compacted mechanically for each $0.5 \mathrm{~m}$. In the process of soil reclamation, the presupporting arch is used to lower the overburden pressure on the lining structure of tunnel to ensure the safety. The physical properties of the backfill soil are summarized in Table 1.

\section{Analytical Model}

According to previous studies, the vertical pressure was known to be either overestimated or underestimated. Both overestimation and underestimation have adverse effects on the design of CCT. It was also found that the holding effect due to the adjacent soil columns with slope can reduce the vertical earth pressure. The backfill-structure-surrounding soil interactions mechanism can be illustrated using two analytical models, shown in Figure 3. Figure 3(a) shows that the CCT is sitting on a valley bottom. This case shows steeper slopes adjacent to the CCT and the distance of valley bottom, $B(B=D+2 b, D$ : width of CCT $(\mathrm{m}), b$ : bottom distance between wall of the CCT to slope $(\mathrm{m})$ ), between two slopes is relatively narrow. Figure 3(b) shows another example which has less steep slopes adjacent to the CCT and a relatively wider bottom between two slopes ( $B$ is greater).

For the former case, the backfill soil tends to slide along the slopes due to the gravitational force. As a result, the interaction force $N$ and $\tau$ acting on the soil provided by the slopes contribute to the uplift forces resisting the relative movement between slopes and backfills subjected to selfweight. Therefore, the soil arching is formed to reduce the vertical earth pressure on the top of CCT (see Figure 3(a)). With the decrease of the slope angle, $\theta\left(^{\circ}\right)$, the rotation of the normal stress, $N$, will reduce the arching effect formed in the backfill. If the slope angle, $\theta$, further decreases and becomes less than the slip surface developed in the backfill due to Rankine active earth pressure $\left(45^{\circ}+\varphi^{\prime} / 2\right)$, the contribution of normal force, $N$, from the adjacent slopes will be less significant. The normal forces, $N_{1}$, and the gravitational force will result in the relative settlements for the soils between the slip surfaces of Rankine active earth pressure and the slopes. Meanwhile, due to the settlement, the shear stress, $\tau_{1}$, developed along the slip surfaces of Rankine active earth pressure will drag the backfill on the top of CCT downwards. Thus, with the increase of distance of $b$, the soil mass between the slip surface and the adjacent slope also increases and results in a greater drag down forces on the backfill on the top of CCT (see Figure 3(b)). However, with an increase of backfill height, the differential settlement between different soil columns (backfill column above the CCT and two backfill columns between slopes and slip surfaces) will be reduced. Although the vertical earth pressure increases, the rate of the increase is reduced. Therefore, for a HFCCT, the phenomenon showing the vertical earth pressure influenced by slope angle and $B / D$ is evident.

Based on the analyses, the vertical earth pressure is relevant to several parameters such as $D, B, \theta$, and $\gamma h$. Meanwhile the relative settlement between different soil columns which are analyzed is related to stiffness of backfill 


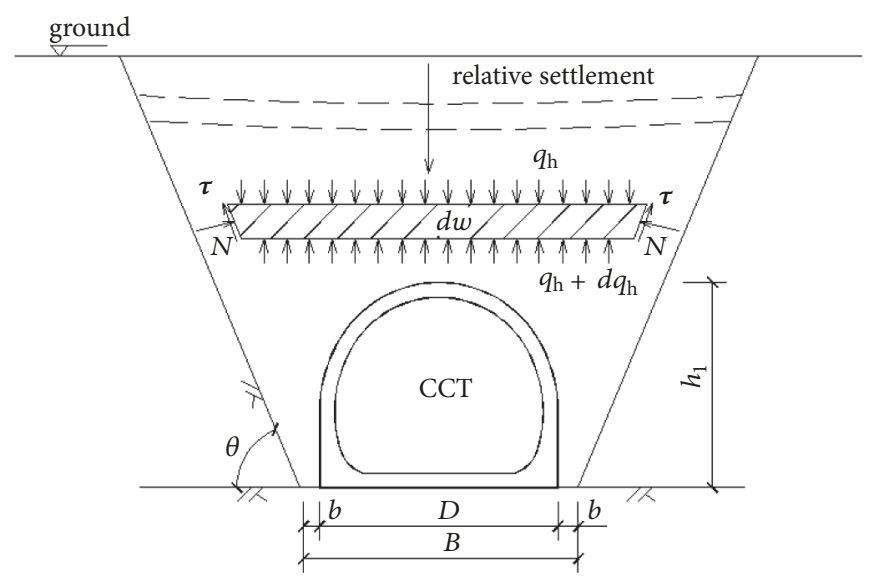

(a)

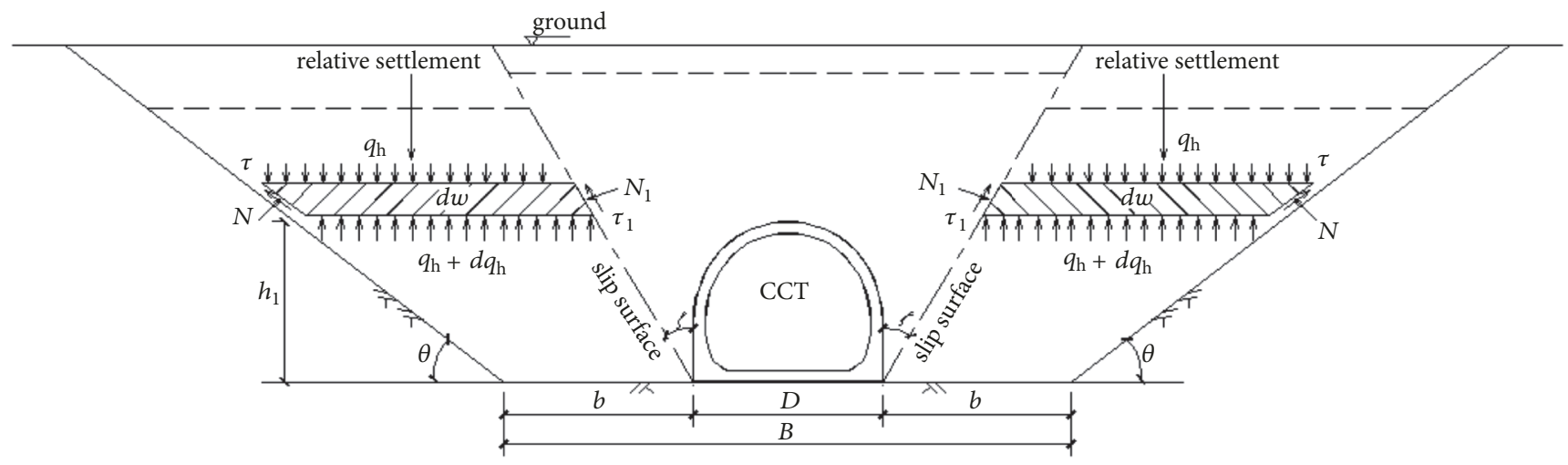

(b) $\mathrm{d}_{\mathrm{w}}$ : unit weight of backfill; $q_{h}$ : the average of earth pressure at a certain depth

FIGURE 3: Analytical models of vertical earth pressure distribution on the top of CCT for (a) greater slope angle and narrower bottom and (b) smaller slope angle and wider bottom.

soils, called the modulus of elasticity, $E(\mathrm{MPa})$. In addition, the patterns of soil stress distribution on the top of soil are different between varying shapes of cross-section [33].

Therefore, the vertical earth pressure, $q(\mathrm{kPa})$, on top of the HFCCT can be expressed as a function of the parameters mentioned above, using the following form:

$$
q=f(S, D, E, \theta, B, \gamma h)
$$

where $S$ represents the influence of cross-sectional of the CCT.

\section{Numerical Analysis}

In order to verify the modified formulas for the vertical earth pressure on the top of HFCCT, finite element analysis was utilized. The parametric studies were conducted to correlate the results to each influential factor for earth pressure.

5.1. Finite Element Analysis. The ANSYS finite element code was used to investigate the earth pressure distribution on the HFCCT subjected to different types of reclamations. The two-dimensional (2-D) finite element analysis was used to conduct the parametric studies. Figure 4(a) shows the meshed model for EI and Figure 4(b) presents the meshed model for TI and the slope angle of the trench is $70^{\circ}$. The element used to model the HFCCT is plane-strain. For the boundary conditions, the two vertical boundaries were restrained horizontally using rollers which only allow vertical deformation; the bottom boundary is fixed. The CCT and the slope were modeled using linearly elastic materials while the backfill for HF and the foundation soil beneath the CCT were modeled using Mohr-Coulomb elastoplastic materials. All the required parameters in the numerical analysis including the material properties for CCT, the engineering properties for backfills, and the foundation soils and the slope characteristics are summarized in Table 2 . The soil properties were obtained from laboratory tests, including direct shear tests and the unconfined compression tests (see Table 2). In the finite element analysis, the interface elements between the soil and structure were simulated using contact element CONTA172 (backfill) and the target element TARGE169 (structure) which are defaulted in ANSYS.

5.2. Parametric Studies. In order to investigate the influence of each factor which was mentioned previously, the four 


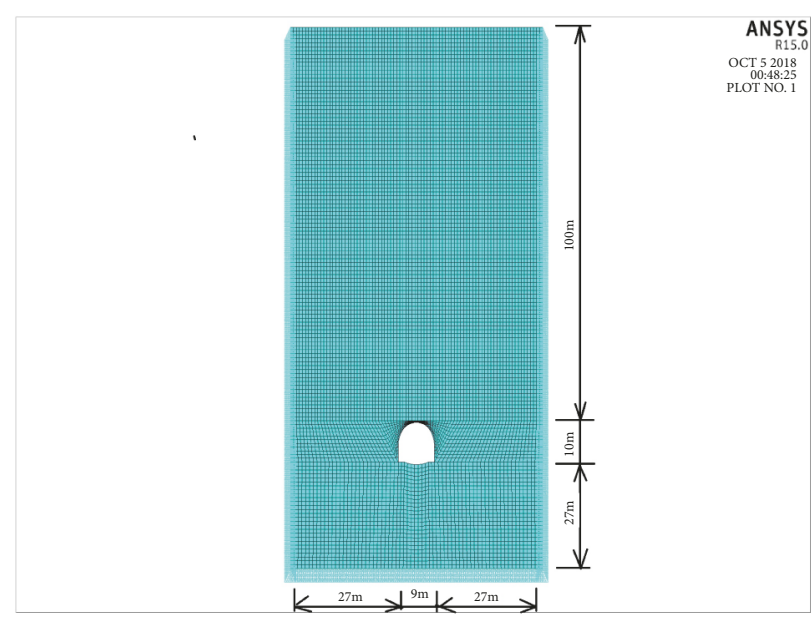

(a)

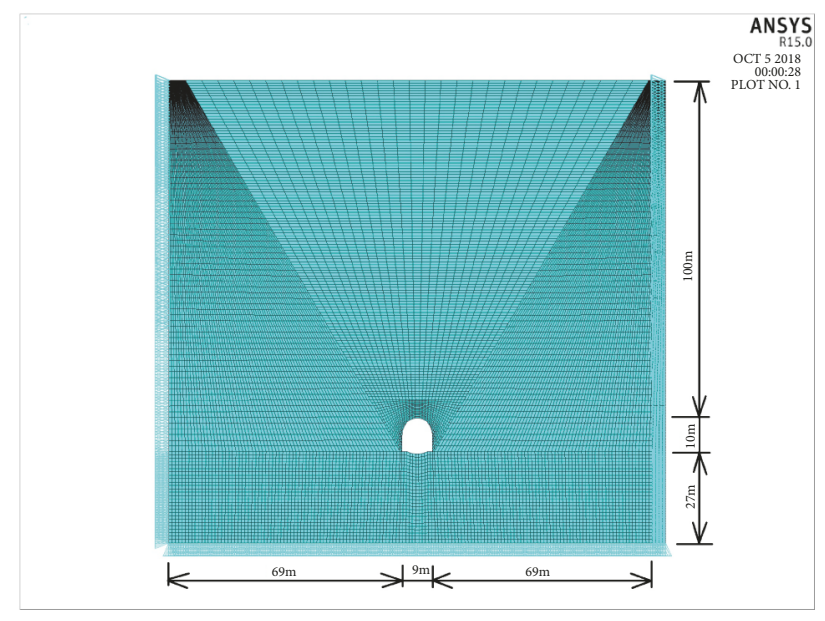

(b) $\mathrm{TI}$

FIGURE 4: Finite element models for (a) embankment installation and (b) trench installation.

TABLE 2: Calculation parameters.

\begin{tabular}{|c|c|c|c|c|c|}
\hline Material & $\begin{array}{c}\text { Elasticity } \\
\text { modulus } \\
(\mathrm{MPa})\end{array}$ & $\begin{array}{l}\text { Poisson's } \\
\text { ratio }\end{array}$ & $\begin{array}{c}\text { Cohesion } \\
(\mathrm{kPa})\end{array}$ & $\begin{array}{c}\text { Friction } \\
\text { angle } \\
\left({ }^{\circ}\right)\end{array}$ & $\begin{array}{c}\text { Unit } \\
\text { weight } \\
\left(\mathrm{kN} / \mathrm{m}^{3}\right)\end{array}$ \\
\hline Backfill & 5.4 & 0.3 & 31.11 & 28.24 & 17.7 \\
\hline Cut-and-cover tunnel & $3 \times 10^{4}$ & 0.167 & - & - & 24 \\
\hline Foundation & 50 & 0.25 & 78 & 32 & 20 \\
\hline Slope & $4 \times 10^{3}$ & 0.2 & - & - & 22 \\
\hline
\end{tabular}

corresponding coefficients, $k_{0}, k_{1}, k_{2}$ and $k_{3}$, are proposed to modify the soil column pressure, $\gamma h$, for backfills. The parametric studies are based on different shapes of CCT sections, the modulus of elasticity for backfill, width of CCT, slope angle, and the ratio of $B / D$. The present study considers two different shapes of CCT cross-sections, rectangular and arch, with the following parameters: width of tunnel, $D=$ $6.85 \mathrm{~m}, 9 \mathrm{~m}$ and $12 \mathrm{~m}$; modulus of elasticity for backfill, $E=$ $10 \mathrm{MPa}, 20 \mathrm{MPa}, 40 \mathrm{MPa}, 80 \mathrm{MPa}$ and $120 \mathrm{MPa}$; slope angle, $\theta=40^{\circ}, 50^{\circ}, 60^{\circ}$ and $70^{\circ}$; the ratio of $B / D=1,1.5$ and 2 . A maximum backfill height $=100 \mathrm{~m}$ was assumed for finite element analysis.

5.3. Analysis Results. Figure 5 shows the results of finite element analysis for the cases of $D=12 \mathrm{~m}$ and the height of backfill $=50 \mathrm{~m}$. Figure 5 shows the contours of vertical stress distribution around the HFCCT for arch (see Figure 5(a)) and rectangular (see Figure 5(b)) cross-sections, respectively. It can be seen that the stress distribution patterns are different around the CCT. The comparisons of the vertical earth pressure distribution on the top of HFCCT with different cross-sectional shape are shown in Figure 6(a). For the rectangular cross-section, the peak value of earth pressure appears on both edges of the CCT, and the lowest value is shown in the middle of the CCT (U distribution). The maximum value appears symmetrically at nearly $0.5 \mathrm{D}$ away from the symmetric axis of CCT. For the arch cross-sectional
CCT, the maximum earth pressure appears in the middle (on the symmetric axis of CCT) and the lowest value at the edges of the top of CCT (inversed U distribution). Using the load equivalent method, the earth pressure distribution on the top of HFCCT can be presented using an equivalently uniformly distributed pressure shown in Figures 6(b) and 6(c). The comparisons between the maximum pressure and averaged equivalent pressure are shown in Figure 6(b) for arch crosssection and in Figure 6(c) for rectangular cross-section.

5.3.1. Influence of Cross-Sectional Shape. $k_{0}$ is the coefficient used to modify the overburden pressure based on different cross-sectional shape of the HFCCT. The dimensionless ratio, $k_{0}$, is defined as the equivalent pressure distribution for rectangular cross-section CCT (see Figure 6(b)) to the equivalent pressure for arch cross-section CCT (see Figure 6(c)) on the HFCCT with similar dimension, D. The $k_{0}$ coefficient can be correlated to another dimensionless ratio, $h / D$, which is the backfill height, $h$ to the diameter of CCT, $D$. Three different dimensions of CCT for two different cross-sectional shapes were analyzed: $D=6.85 \mathrm{~m}, 9 \mathrm{~m}$ and $12 \mathrm{~m}$, respectively. The results showing the relationship between $k_{0}$ and $h / D$ are presented in Figure 7.

As it can be seen in Figure 7, the effect of $k_{0}$ is significant when the $h / D$ ratio is less than 2 . If the $h / D$ ratio is greater than 2 , the coefficient $k_{0}$ of the three widths studied is close to 1.0 regardless of the $h / D$ ratio. These results mean that the 


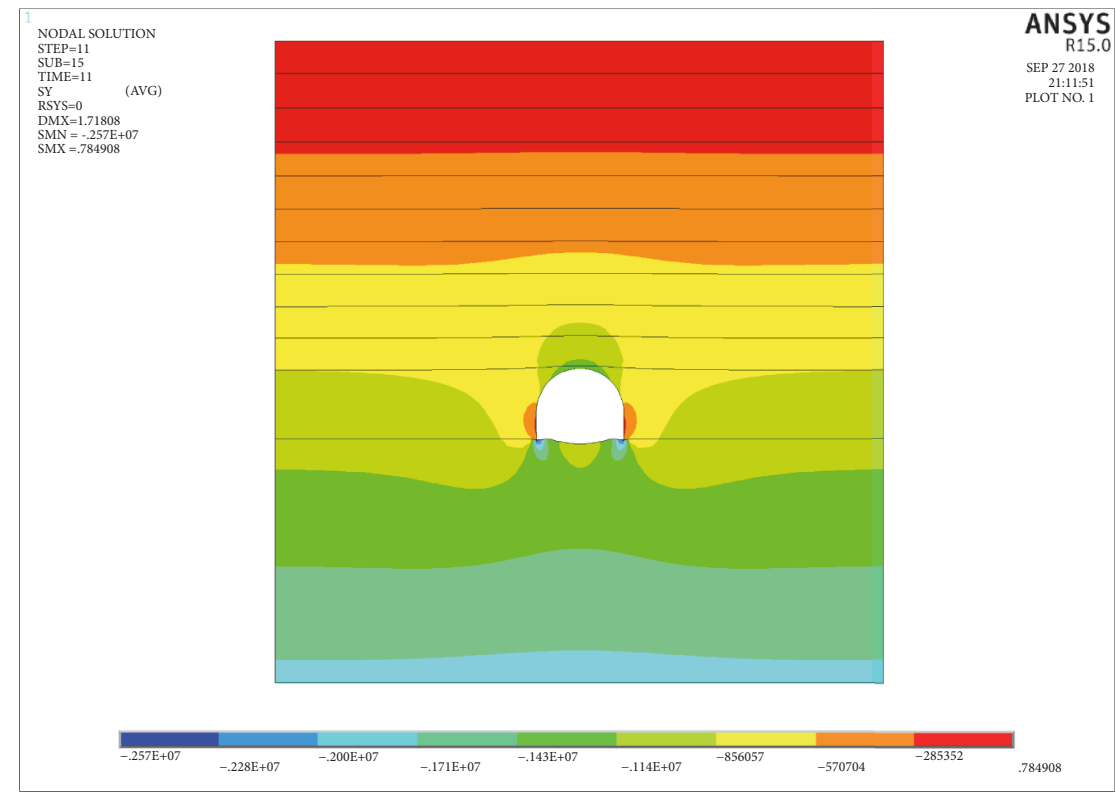

(a)

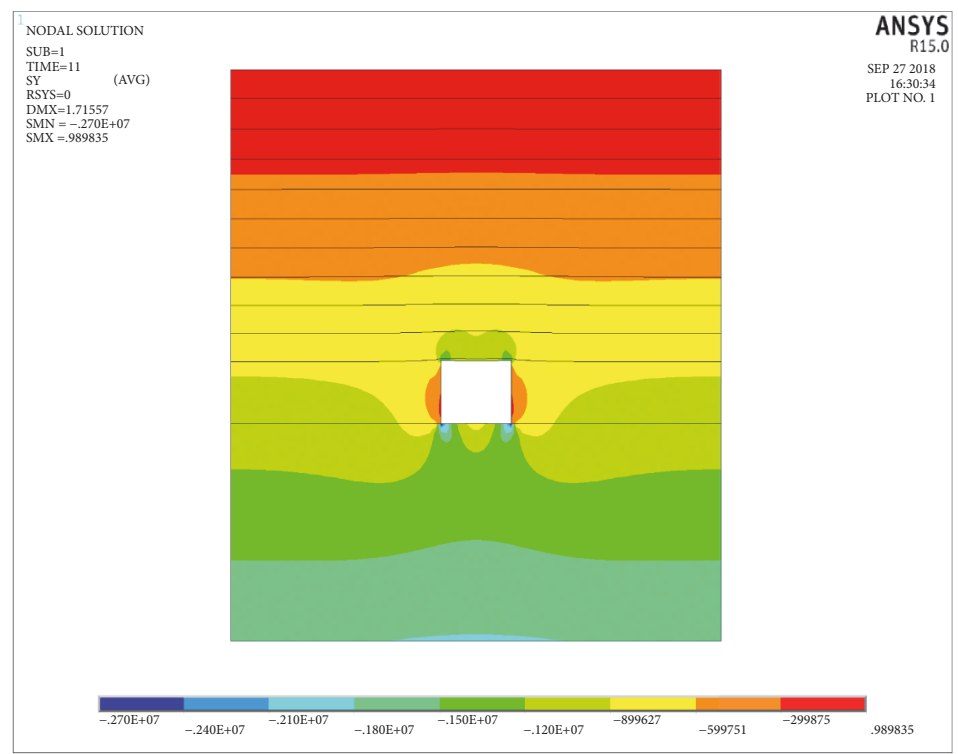

(b)

FIGURE 5: Contours of the vertical earth pressure on the top of the HFCCT for (a) arch cross-section and (b) rectangular cross-section.

coefficient, $k_{0}$, is independent on shape effect for a higher $\mathrm{h} / \mathrm{D}$. Thus, for the HFCCT, the $k_{0}=1.0$, regardless of the shape of CCT's cross-sections (rectangle or arch). That would also mean the effect of shape on the vertical earth pressure can be ignored for the HFCCT, but should be considered if $h / D$ less than 2.

5.3.2. Influence of Stiffness of Backfill. According to previous studies, the influences of internal friction angle, $\phi$, and the cohesion, $c$, of the backfill on vertical earth pressure at the top of HFCCT are less significant [32]. However, the modulus of backfill soil, $E$, was found to have significant influence on vertical earth pressure. In the numerical analysis, the strength parameters, $c$ and $\phi$ of the backfill soil, were assumed to be invariable and homogeneous, and different values (10MPa, $20 \mathrm{MPa}, 40 \mathrm{MPa}, 80 \mathrm{Mpa}$, and $120 \mathrm{MPa}$ ) for backfill modulus of elasticity, $E$, were studied, respectively. Figure 8 shows the contours of vertical earth pressure distribution for the cases using $E=10 \mathrm{MPa}$ and $40 \mathrm{MPa}$. The equivalent earth pressures on the top of HFCCT for these two examples are $1.13 \mathrm{MPa}$ and 1.07MPa, respectively. Similarly, the analysis for other modulus values was also conducted. For $E=20 \mathrm{MPa}, 80 \mathrm{MPa}$, and $120 \mathrm{MPa}$, the equivalent pressures on the top of HFCCT 


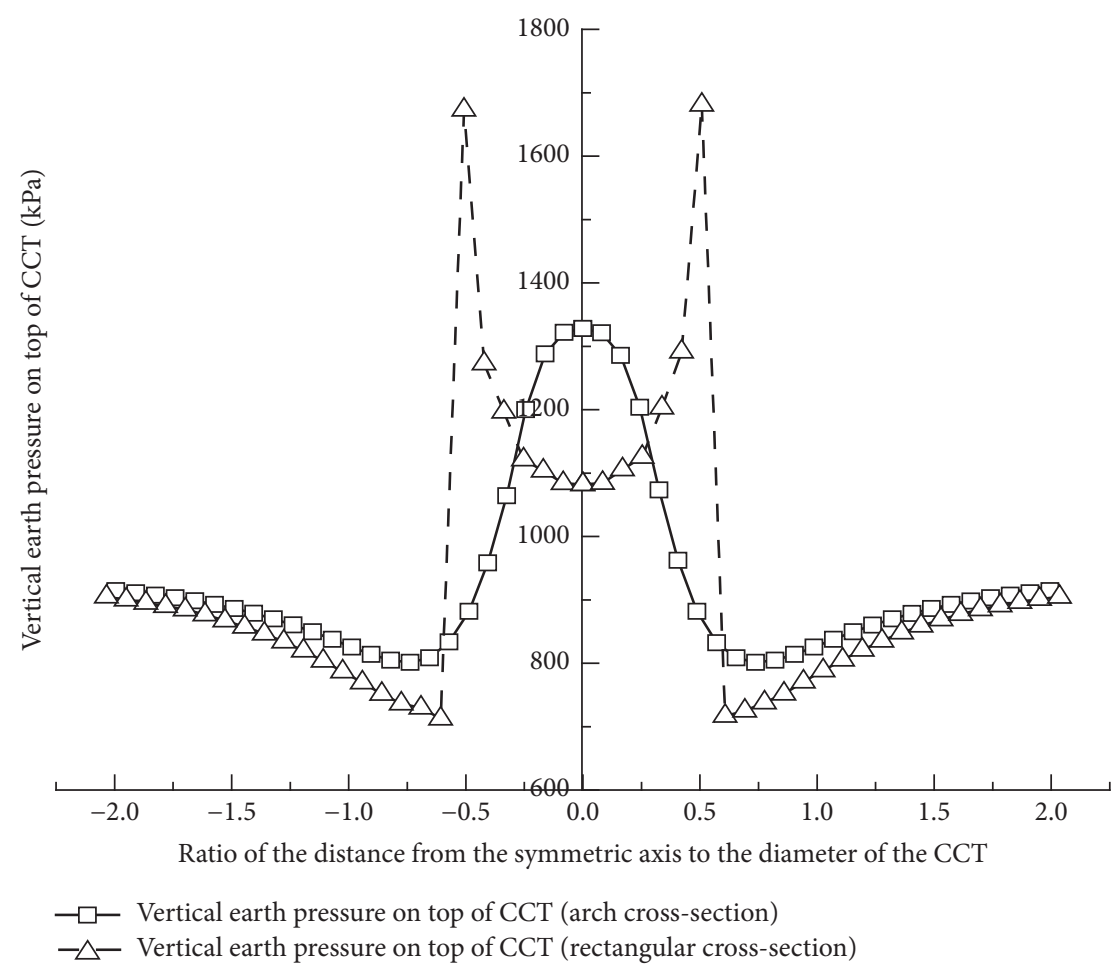

(a)

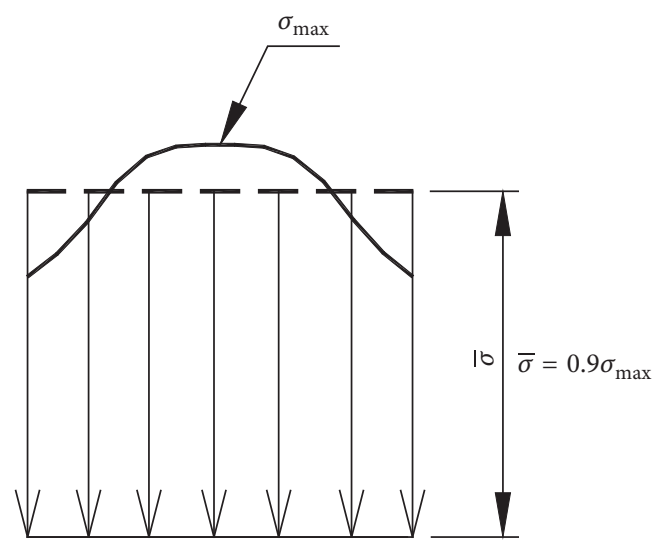

(b)

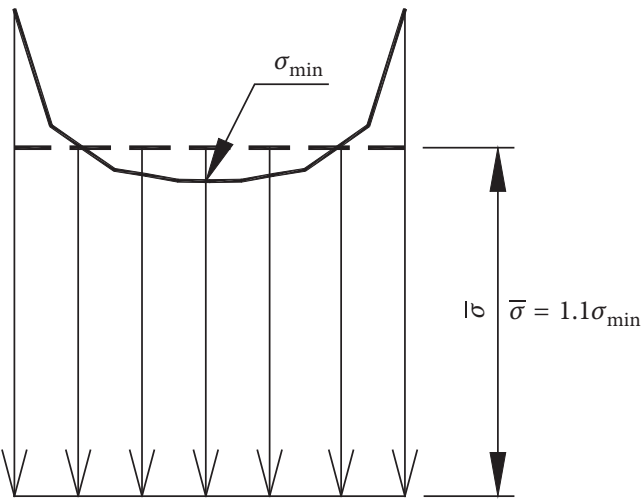

(c)

FiguRE 6: (a) Comparisons of vertical earth pressure distribution for different cross-sectional shape of CCT; (b) equivalent vertical earth pressure distribution for arch cross-section; (c) equivalent vertical earth pressure distribution for rectangular cross-section.

are $1.10 \mathrm{MPa}, 1.04 \mathrm{MPa}$, and $1.02 \mathrm{MPa} . k_{1}$ is a coefficient which is corresponding to the influence of the stiffness of the backfill. The dimensionless ratio, $k_{1}$, is defined as "the equivalent pressure distribution for different modulus of elasticity, $E$, to the equivalent pressure for modulus of elasticity, $E=5.4 \mathrm{MPa}$ on the HFCCT." The relationship between $k_{1}$ and $h / D$ is shown in Figure 9.

In Figure 9, the $k_{1}$ coefficient decreases when the ratio, $h / D$, increases. Meanwhile, the reduction rate increases if the modulus of elasticity, $E$, is greater (see Figure 8(a)). Based on these findings, each curve for the relationships between $k_{1}$ and $h / D$, considering the findings of different modulus of elasticity studies, can be mathematically expressed using the functions of $h / D$. The individual equation for $k_{1}$ subjected to different modulus of elasticity, $E$, is shown in Figure 9(a). To further demonstrate a possible correlation between the influence of the modulus, $E$, to $k_{1}$, assuming $k_{1}=k_{1}{ }^{*} \cdot \ln (h / D)+1$, and $k_{1}{ }^{*}=f(E)$, the relationship between $k_{1} *$ and $E$ is plotted in Figure 9 (b). The equation provided by simple logarithmic regression with $R^{2}=0.9721$ is expressed in

$$
k_{1}^{*}=-0.015 \ln (E)+0.0133
$$

Therefore, the general form of the $k_{1}$ can be written in a mathematical form as

$$
k_{1}=[-0.015 \ln (E)+0.0133] \ln \left(\frac{h}{D}\right)+1
$$




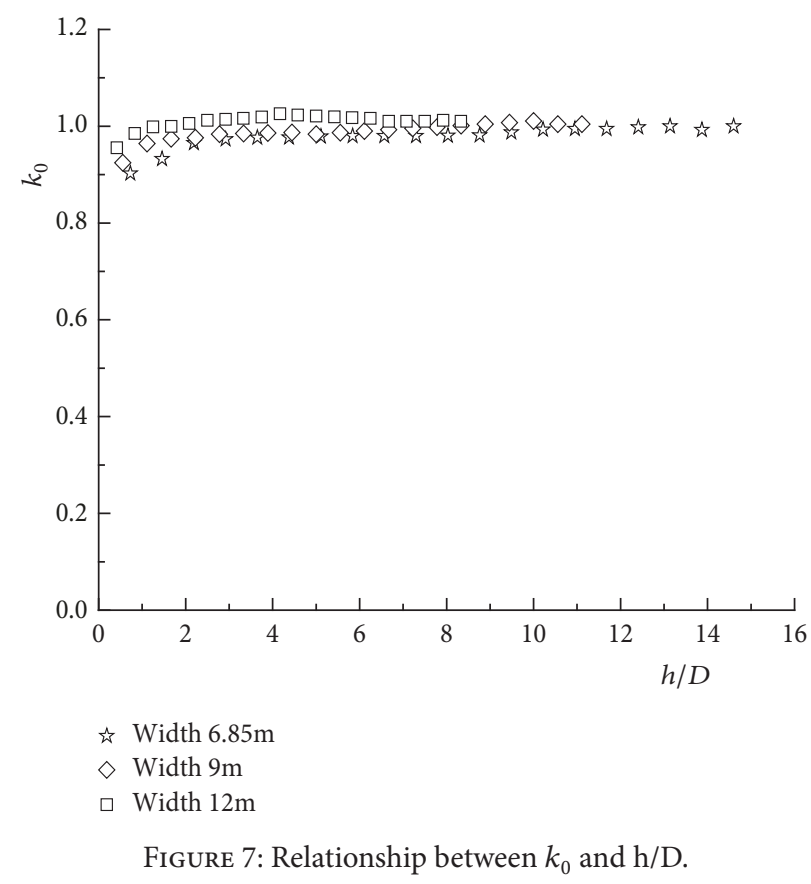

Thus, the modulus of elasticity, E, has a positive influence on earth pressure reduction for a higher backfill. With the increase of fill height, the reduction is more notable. Thus, the $k_{1}$ modification is necessary for the HFCCT.

\subsubsection{Influence of Dimension. The dimension of CCT specif-} ically refers to the width of CCT. Figure 10 shows the results of finite element analysis for the vertical earth pressure distribution for the two different widths of CCT: $6.85 \mathrm{~m}$ (Figure 10(a)) and $12 \mathrm{~m}$ (Figure 10(b)). It can be seen from the stress contours that the equivalent earth pressures are $1.30 \mathrm{MPa}$ and $1.13 \mathrm{MPa}$, respectively. The results show that the tunnel width is relevant to the induced equivalent earth pressure, and a CCT with a smaller section will result in a higher equivalent earth pressure. A coefficient, $k_{2}$, is introduced to modify the soil column pressure, $\gamma h$, taking into account the effect of dimension.

Three different widths of CCT were studied: $D=6.85 \mathrm{~m}$, $9 \mathrm{~m}$ and $12 \mathrm{~m}$. The coefficient for modifying the size effect of CCT was defined to be $k_{2}$, having the equivalent pressure distribution for differing widths of tunnel to weight of soil column, $\gamma h$, on the HFCCT. The results of $k_{2}$ versus $h / D$ are plotted and shown in Figure 11. As it can be seen from Figure 10, the influence of the size of HFCCT nonlinearly increases with $h / D$. Meanwhile, the smaller size of CCT will result in a higher value of $k_{2}$. The three curves of regression are found to be highly relevant to $h / D$ and the corresponding equations for $k_{2}$ subjected to different widths of CCT are also shown in Figure 11. These $k_{2}$ corresponding to different width, $D$, are expressed in mathematical forms based on the function of $h / D$. The $k_{2}$ can be written in the form of $k_{2}=$ $k_{2}{ }^{*} \cdot(h / D)^{0.1}$, such that values of $k_{2}{ }^{*}(1.2787,1.2131$ and 1.1604$)$ are corresponding to $D=6.85 \mathrm{~m}, 9 \mathrm{~m}$, and $12 \mathrm{~m}$, respectively. To further correlate the equation to the width of CCT, $D$, the relationship between $k_{2} *$ and $D$ is plotted in Figure 11(b). Assuming $k_{2}{ }^{*}=f(D)$, the equation for this linear regression curve with $R^{2}=0.9753$ on Figure 11(b) can be expressed in

$$
k_{2}^{*}=-0.0226 D+1.43
$$

Accordingly, the general form for $k_{2}$ can be mathematically expressed using (5). The $k_{2}$ is a value which is greater than 1.0, and the value increases when the width of CCT decreases. As such, the effect of $k_{2}$ will amplify the overburden pressure, $\gamma h$, and the amplification increases when the size of CCT decreases.

$$
k_{2}=(-0.0226 D+1.43)\left(\frac{h}{D}\right)^{0.1}
$$

5.3.4. Influence of Slope Angle and B/D. Figure 12 shows that the results of finite element analysis for the vertical earth pressure distribution considering two different slop angles, $\theta$, and the ratio, $B / D$. Figure 12(a) shows the example for $\theta$ $=40^{\circ}$ and $B / D=2$, while Figure $12(\mathrm{~b})$ shows the case for $\theta=$ $70^{\circ}$ and $B / D=1$. It can be seen from the stress contours that the equivalent earth pressures are $1.02 \mathrm{MPa}$ and $0.52 \mathrm{MPa}$, respectively. The results show that the coupling of $\theta$ and $B / D$ are highly relevant to the induced equivalent vertical earth pressure. A CCT with a smaller $\theta$ and a greater $B / D$ was found to result in a higher equivalent vertical earth pressure.

A coefficient, $k_{3}$, is defined to modify the soil column pressure, $\gamma h$, based on the slope angle and the ratio of $B / D$. It has been found that the width of bottom of valleys and the slope angle have some constraints on the high backfill. Therefore, the slope angle and the ratio of $B / D$ should not be considered separately. The coupling influence of $\theta$ and $\mathrm{B} / \mathrm{D}$ are presented in the mathematical form of $k_{3}$.

In the finite element analysis, three different $B / D(1.0,1.5$, and 2.0) and four slope angles, $\theta,\left(40^{\circ}, 50^{\circ}, 60^{\circ}\right.$ and $\left.70^{\circ}\right)$ were 


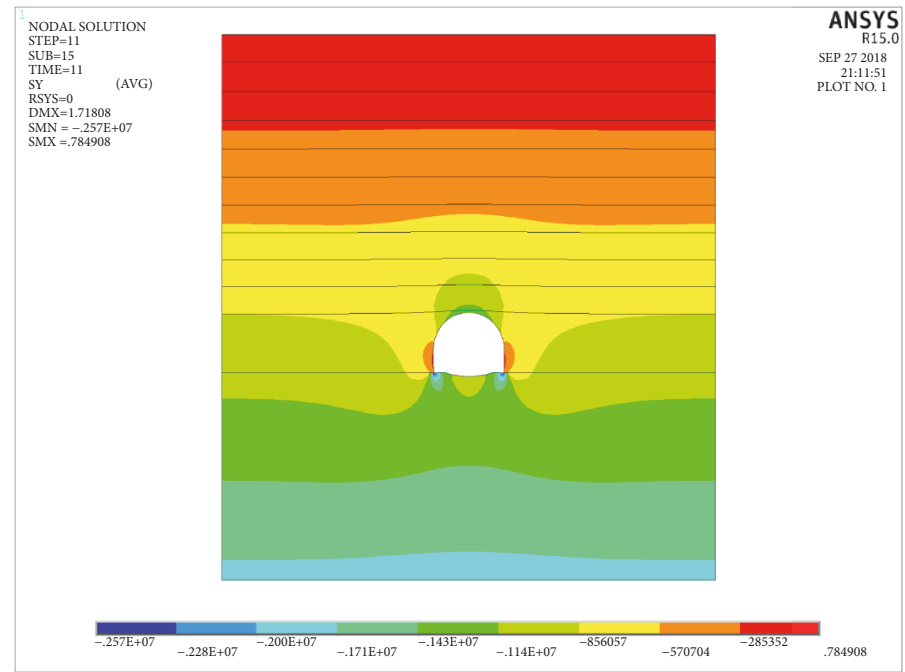

(a)

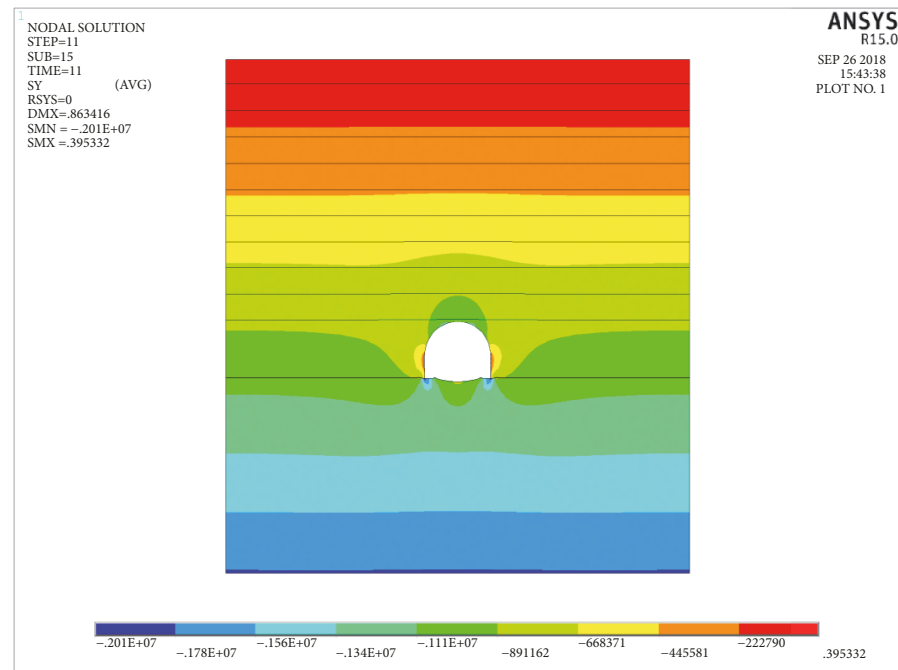

(b)

FIGURE 8: Contours of vertical earth pressure distribution surrounding the HFCCT for (a) $E=10 \mathrm{Mpa}$ and (b) $E=40 \mathrm{MPa}$.

considered, respectively. For different $B / D$ values, the results are as follows.

For $B / D=1.0$ with $\theta=40^{\circ}, 50^{\circ}, 60^{\circ}$ and $70^{\circ}$, the analysis results are shown in Figure 13. In Figure 13(a), based on the relationships of $k_{3(1)}$ versus $h / D$, four equations for $k_{3(1)}$ corresponding to different $\theta$ are presented. To further include the effects of $\theta$ in the these forms, it is assumed $k_{3(1)}=$ $k_{3(1)}{ }^{*} \cdot \ln (h / D)+k_{3(1)}{ }^{* *}$, while $k_{3(1)}{ }^{*}=f(\theta)$ and $k_{3(1)}{ }^{* *}=f(\tan$ $\theta)$. Figure 13(b) shows the relationship between $k_{3(1)}{ }^{*}$ and $\theta$. Through the regression using a straight line with $R^{2}=$ 0.9985, the equation for $k_{3(1)}{ }^{*}$ is shown in Figure 13(b). Figure 13(c) shows the relationship between $k_{3(1)}{ }^{* *}$ and tan $\theta$. The equation of $k_{3(1)}{ }^{* *}$ is given. Therefore, the $k_{3(1)}$ can be mathematically expressed using

$$
\begin{aligned}
k_{3(1)}= & (-0.0038 \theta+0.0524) \ln \left(\frac{h}{D}\right)-0.0902 \tan \theta \\
& +1
\end{aligned}
$$

Similarly, for $\mathrm{B} / \mathrm{D}=1.5$ and 2.0 and $\theta=40^{\circ}, 50^{\circ}, 60^{\circ}$ and $70^{\circ}$, the methods to obtain the general forms for $k_{3(1.5)}$ and $k_{3(2)}$ are shown in Figures 14 and 15, respectively. The mathematical forms of $k_{3(1.5)}$ and $k_{3(2)}$ are shown as

$$
\begin{aligned}
k_{3(1.5)}= & (-0.0041 \theta+0.0693) \ln \left(\frac{h}{D}\right)-0.062 \tan \theta \\
& +1 \\
k_{3(2)}= & (-0.0042 \theta+0.0806) \ln \left(\frac{h}{D}\right)-0.0345 \tan \theta \\
& +1
\end{aligned}
$$

In order to obtain the general forms for $k_{3}$, it is assumed $k_{3}=\left(k_{31} \theta+k_{32}\right) \ln (h / D)-k_{33} \tan \theta+1\left(k_{31}, k_{32}\right.$ and $k_{33}$ are the 


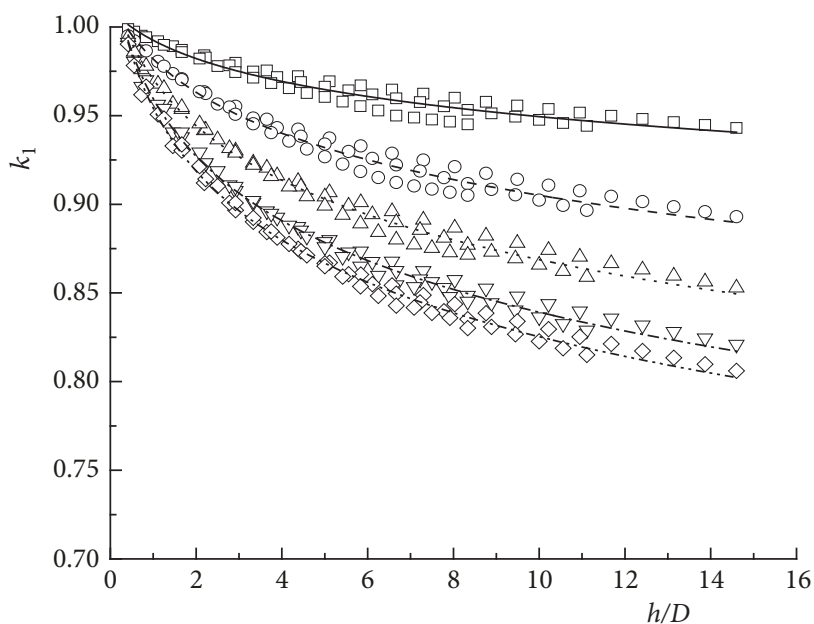

$\mathrm{E}=10 \mathrm{MPa} \quad-\quad k_{1}=-0.018 \ln \left(\frac{h}{D}\right)+1 \quad \mathrm{R}^{2}=0.9035$

$\mathrm{E}=20 \mathrm{MPa} \quad-\quad k_{1}=-0.033 \ln \left(\frac{h}{D}\right)+1 \quad \mathrm{R}^{2}=0.9433$

$\mathrm{E}=40 \mathrm{MPa} \quad \cdots \quad k_{1}=-0.044 \ln \left(\frac{h}{D}\right)+1 \quad \mathrm{R}^{2}=0.9708$

$\mathrm{E}=80 \mathrm{MPa} \quad-\quad k_{1}=-0.052 \ln \left(\frac{h}{D}\right)+1 \quad \mathrm{R}^{2}=0.9838$

$\mathrm{E}=120 \mathrm{MPa}-\cdots \quad k_{1}=-0.055 \ln \left(\frac{h}{D}\right)+1 \quad \mathrm{R}^{2}=0.9879$

(a)

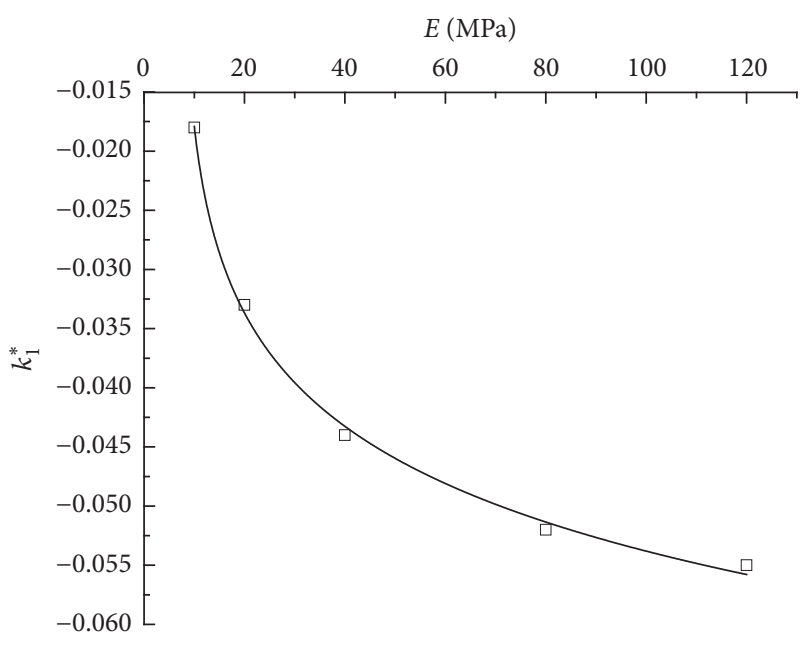

$-k_{1}^{*}=-0.015 \ln (E)+0.0133$

$\mathrm{R}^{2}=0.9721$

(b)

Figure 9: Relationship between (a) $k_{1}$ with $h / D$ and (b) $k *_{1}$ with $h / D$.

functions of $B / D$ ). The relationships for $k_{31}$ versus $B / D, k_{32}$ versus $B / D$ and $k_{33}$ versus $B / D$ are plotted in Figure 16 , respectively. Based on the results shown in Figures 16(a), 16(b), and 16(c), the general form for $k_{3}$ is established. The mathematical for of $k_{3}$ can be expressed using

$$
\begin{gathered}
k_{3}=\left[\left(-0.0004 \frac{B}{D}-0.0034\right) \theta+0.0282 \frac{B}{D}+0.0251\right] \\
\cdot \ln \left(\frac{h}{D}\right)+\left(0.0548 \frac{B}{D}-0.1447\right) \tan \theta+1 .
\end{gathered}
$$

$k_{3}$ is a coefficient which is usually less than 1.0 and can be significantly reduced up to $70 \%$, depending on the coupling effect of slope angle, $\theta$, and the ratio, $B / D$. This reduction comes from the contribution of the normal holding stress of the valley slopes adjacent to the backfills. With the increase of the fill height, the reduction is more obvious. In practical engineering, if the influence for coefficient of $k_{3}$ can be considered carefully, the significant reduction on vertical earth pressure will enhance the safety of existing CCT and avoid an overconservative design by considering the vertical earth pressure for the HFCCT.
With these four coefficients determined and demonstrated as influential factors, the vertical earth pressure on the top of the HFCCT should be modified as follows:

$$
q=k_{0} k_{1} k_{2} k_{3} \gamma h
$$

where $k_{0}, k_{1}$, and $k_{2}$ are the influence coefficients of crosssection shape, elasticity modulus, and the width of CCT, respectively. $k_{3}$ is the coupling effect of slope angle, $\theta$, and the ratio, $B / D$.

\section{Numerical Verification of Proposed Method}

In order to verify the feasibility of this proposed equation which includes four coefficients of modification: $k_{0}, k_{1}, k_{2}$, and $k_{3}$, an example shown below is a HFCCT that has a dimension in width, $D=13.76$. The modulus of elasticity of soil, $E$, is $20 \mathrm{MPa}$, and the other properties are consistent with those parameters shown in Table 1 . Two cases (Case I: $B / D=$ 1.5, $\theta=60^{\circ}$; and Case II: $B / D=2.0, \theta=40^{\circ}$ ) were considered, and the computed results using this proposed method are compared to results using soil column theory $(\gamma h)$ and finite element analysis using ANSYS. The comparisons are shown in Figure 17. The average relative error is $1.14 \%$ for the results using the proposed method and the numerical analysis. The 


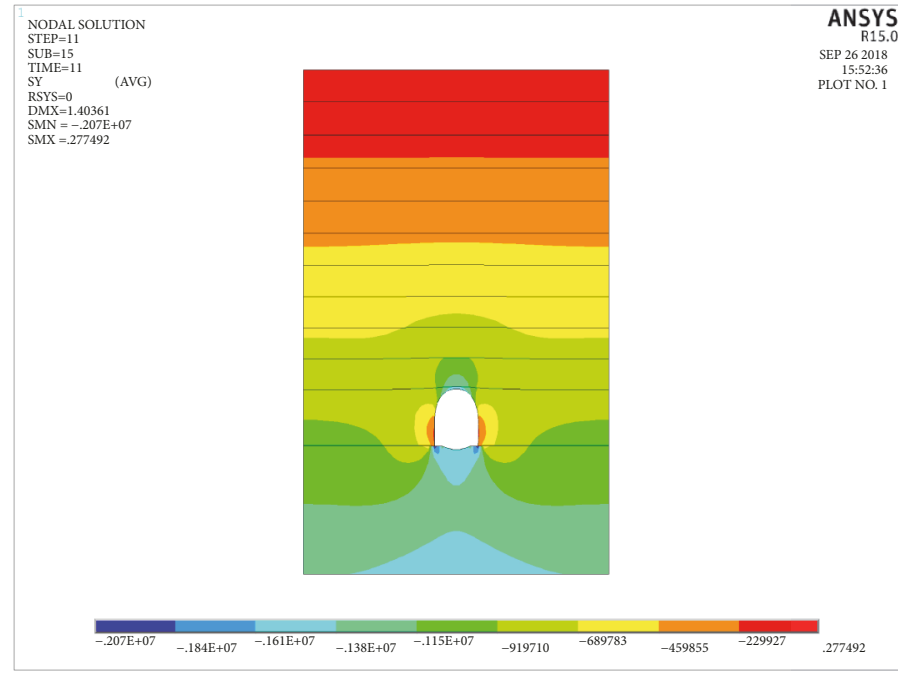

(a)

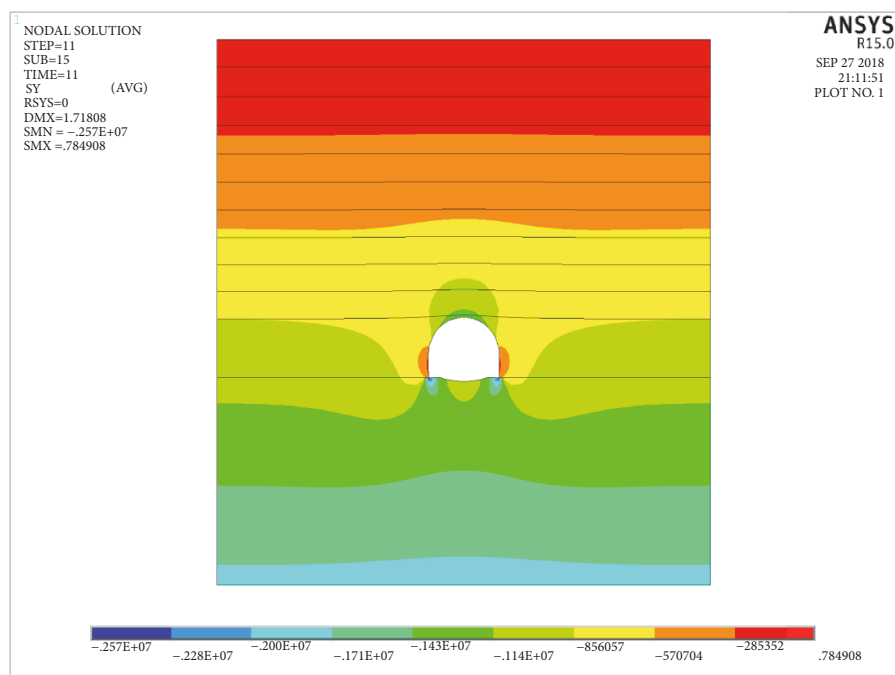

(b)

FIGURE 10: Vertical earth pressure distribution around HFCCT for (a) $D=6.85 \mathrm{~m}$ and and (b) $12 \mathrm{~m}$.

proposed method is effective in avoiding the complicated numerical analysis considering all influential factors.

Selecting $h=50 \mathrm{~m}$, the detailed steps to obtain each coefficient to modify the soil column pressure, $\gamma$ h, and use the proposed method are shown as follows.

(1) Calculation of $k_{0}$. Since the sectional shape of a CCT was found to have little influence on the vertical earth pressure for the HFCCT, thus, assume $k_{0}=1$ is reasonable.

(2) Calculation of $k_{1}$. Calculating $k_{1}$ using equation (3), $k_{1}=0.959$ is obtained.

$$
k_{1}=[-0.015 \ln (E)+0.0133] \ln \left(\frac{h}{D}\right)+1
$$

$$
\begin{aligned}
& =[-0.015 \ln (20)+0.0133] \ln \left(\frac{50}{13.76}\right)+1 \\
& =0.959
\end{aligned}
$$

(3) Calculation of $k_{2}$. According to equation (5), the $k_{2}=1.273$ is computed as follows:

$$
\begin{aligned}
k_{1} & =(0.0226 D+1.43)\left(\frac{h}{D}\right)^{0.1} \\
& =(0.0226 \times 13.76+1.43)\left(\frac{50}{13.76}\right)^{0.1}=1.273
\end{aligned}
$$




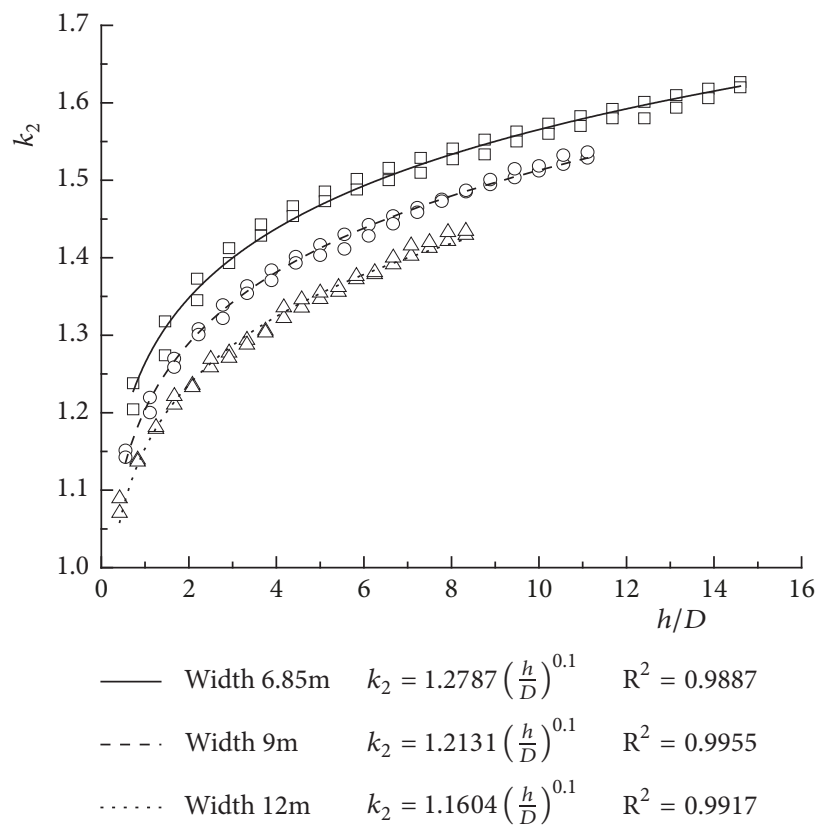

(a)

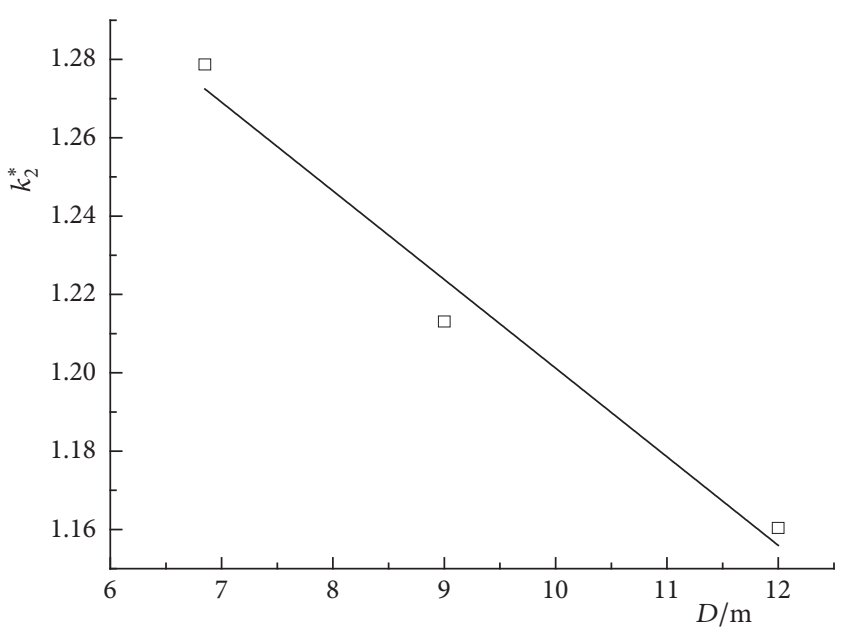

$$
\begin{aligned}
k_{2}^{*} & =-0.0226 D+1.43 \\
\mathrm{R}^{2} & =0.9753
\end{aligned}
$$

(b)

Figure 11: Relationship between (a) $k_{2}$ and $h / D$ and (b) $k *_{2}$ with $h / D$.

(4) Calculation of $k_{3}$. Calculating according to equation (9), the detailed calculations and $k_{3}=0.669$ are shown as follows:

$$
\begin{aligned}
k_{3} & =\left[\left(-0.0004 \frac{B}{D}-0.0034\right) \theta+0.0282 \frac{B}{D}+0.0251\right] \\
\cdot & \ln \left(\frac{h}{D}\right)+\left(0.0548 \frac{B}{D}-0.1447\right) \tan \theta+1 \\
& =\left[(-0.0004 \times 1.5-0.0034) \times 60^{\circ}+0.0282 \times 1.5\right. \\
& +0.0251] \ln \left(\frac{50}{13.76}\right)+(0.0548 \times 1.5-0.1447) \\
\cdot & \tan 60^{\circ}+1=0.669
\end{aligned}
$$

After determining $k_{0}, k_{1}, k_{2}$, and $k_{3}$, the final vertical earth pressure can be modified using equation (10) for the HFCCT (see below). The vertical earth pressure is $722.80 \mathrm{kPa}$ on the top of HFCCT for the backfill height, $h=50 \mathrm{~m}$ :

$$
\begin{aligned}
q & =k_{0} k_{1} k_{2} k_{3} \gamma h \\
& =1 \times 0.959 \times 1.273 \times 0.699 \times 17.7 \times 50 \\
& =722.80 \mathrm{kPa}
\end{aligned}
$$

The results for other backfill heights can be obtained using the same mathematical procedures and substituting the appropriate values. Close examination of Figure 17 leads to several findings that can be addressed herein.
TABLE 3: Testing schemes.

\begin{tabular}{lc}
\hline Case & Cross-Section Shape \\
\hline S1 & Rectangle \\
S2 & Arch \\
\hline
\end{tabular}

\section{Experimental Verification of Proposed Method}

In order to verify the feasibility of this proposed equation which includes four coefficients of modification: $k_{0}, k_{1}$, $k_{2}$, and $k_{3}$, we designed the experimental test. A rigid steel tank with dimensions of $180 \mathrm{~cm} \times 120 \mathrm{~cm} \times 150 \mathrm{~cm}$ (length $\times$ width $\times$ height) for the tests and the dimensions of the model CCT with either an arched or rectangular cross-sectional shape is $120 \mathrm{~cm}$ in length, $28 \mathrm{~cm}$ in height, and $56 \mathrm{~cm}$ in width. Figure 18(a) presents a cross-sectional representation of the HFCCT apparatus that includes both the rectangular and arched CCT's design. In the model, the two slopes were formed using concrete, which is assumed to be rigid. The slope angle of the two slopes in the tank was defaulted to be $70^{\circ}$. In order to record the distribution of the earth pressure on top of the CCT, nine earth pressure cells (No. 1 to No. 9) were installed on top of the first-layer soil to record the earth pressure distribution on top of the CCT, as shown in Figure 18(b).

Table 3 summarizes the conditions for the two tests. S1 and S2 had rectangle and arch cross-sectional shape, respectively.

The physical and engineering properties of the backfill soil from the laboratory tests are summarized in Table 4. 


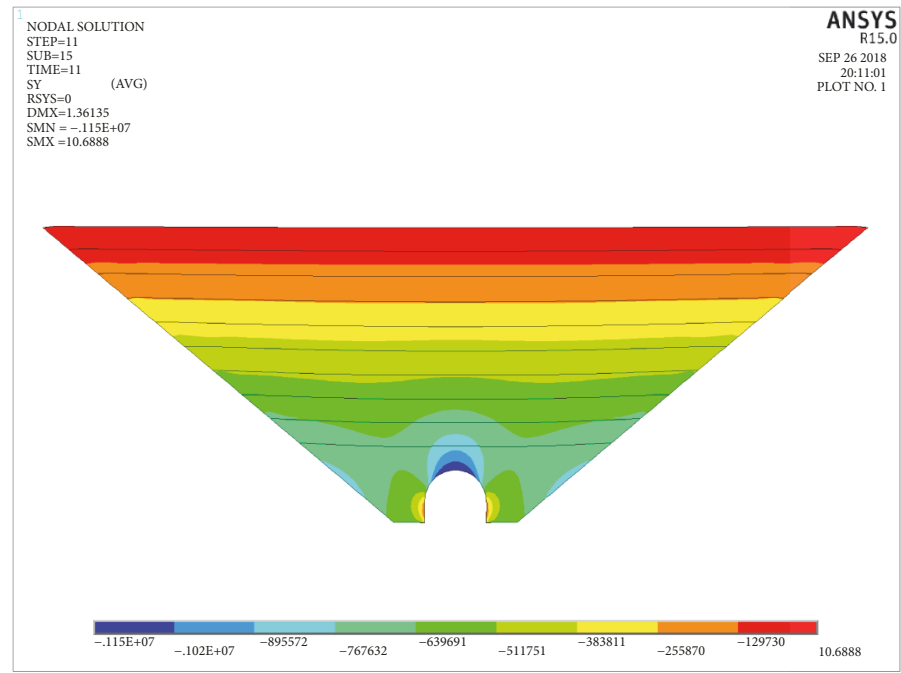

(a)

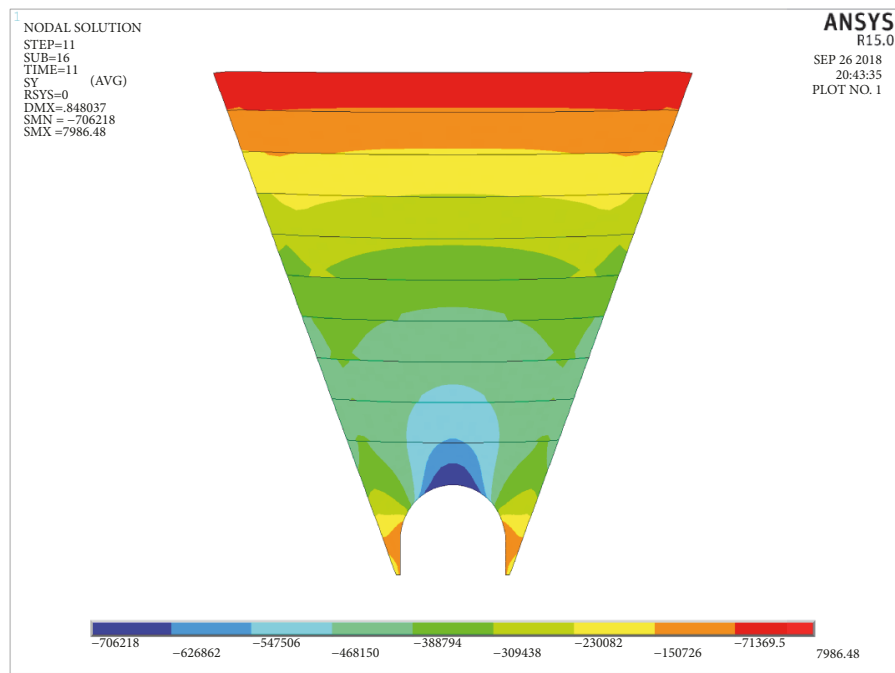

(b)

Figure 12: Contours of vertical earth pressure distribution around the HFCCT with different slope angle, $\theta$ and $B / D$ : (a) $\theta=40^{\circ}, B / D=2$; (b) $\theta=70^{\circ}, B / D=1$.

TABLE 4: Physical properties of backfill soil.

\begin{tabular}{|c|c|c|c|c|c|}
\hline $\begin{array}{l}\text { Optimum } \\
\text { moisture content }\end{array}$ & $\begin{array}{l}\text { Maximum } \\
\text { dry density }\end{array}$ & $\begin{array}{c}\text { Unit } \\
\text { weight }\end{array}$ & Cohesion & $\begin{array}{c}\text { Internal friction } \\
\text { angle }\end{array}$ & $\begin{array}{l}\text { Young's } \\
\text { modulus }\end{array}$ \\
\hline $\mathrm{W}_{\text {opt }}(\%)$ & $\gamma_{\mathrm{d}}\left(\mathrm{g} / \mathrm{cm}^{3}\right)$ & $\gamma\left(\mathrm{kN} / \mathrm{m}^{3}\right)$ & $c(\mathrm{kPa})$ & $\phi\left(^{\circ}\right)$ & $E(\mathrm{MPa})$ \\
\hline 15.25 & 1.58 & 9.47 & 31.1 & 28.3 & 5.4 \\
\hline
\end{tabular}

In order to model the actual backfill construction over an HFCCT, the CCT was installed between the slope firstly; secondly, fill and compact the first layer of soil above the CCT, and install 9 earth pressure cells on top of the first layer; thirdly, repeat the fill and compaction process for the subsequent layer(s) until the maximum backfill height is reached. Meanwhile, measure the earth pressure while filling the backfill at each stage.
Figure 19 compares the computational results for experiments, numerical analyses, and the modified equation for the backfill height of $90 \mathrm{~cm}$. The results summarized in Figure 19 are based on a vertical earth pressure coefficient, $\lambda=$ vertical earth pressure on top of CCT $/ \gamma h$. This results show that the estimations of vertical earth pressure on the top of HFCCT using the proposed method are nearly consistent with the results using finite element analysis; the experimental results 


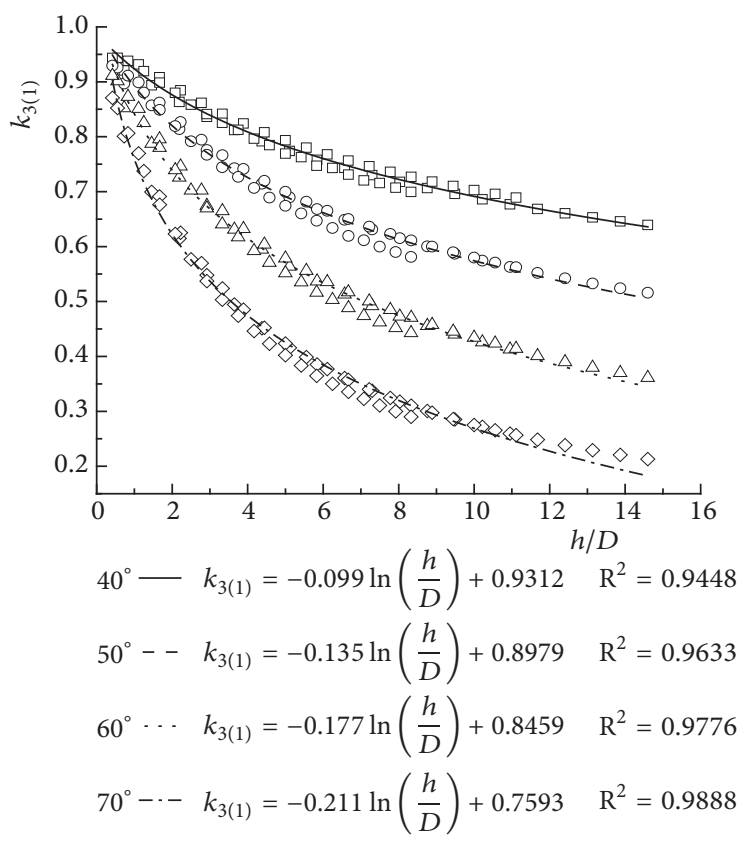

(a)

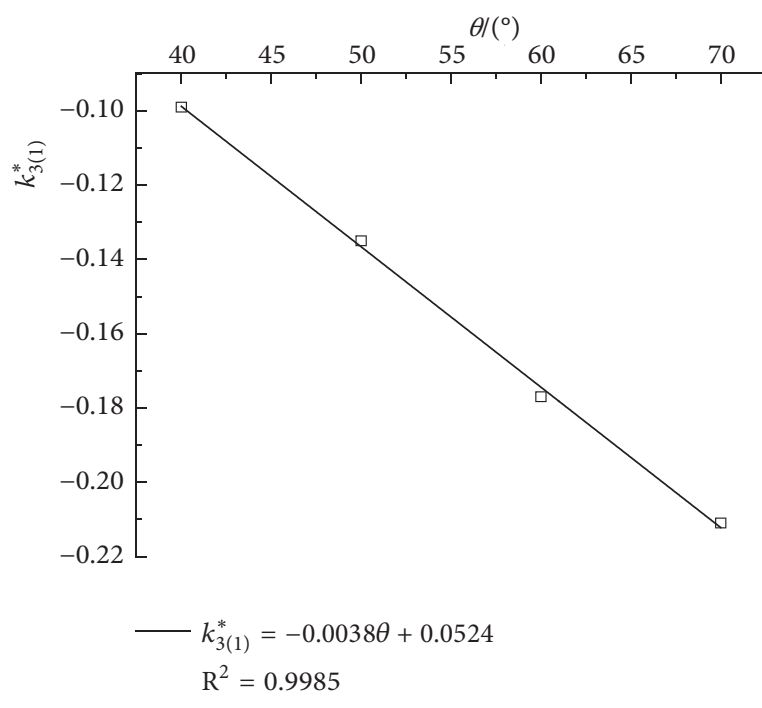

(b)

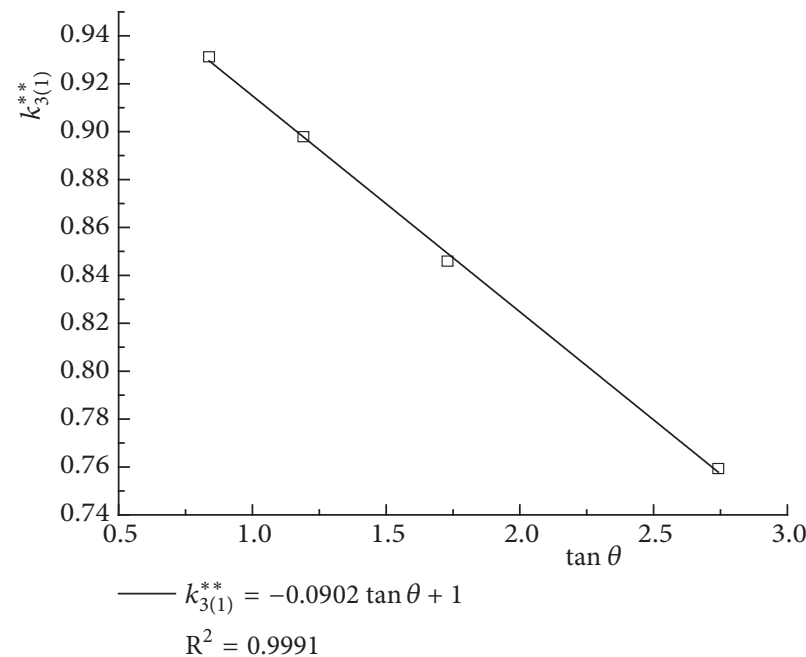

(c)

FIGURE 13: Relationship between (a) $k_{3(1)}$ and $h / D$; (b) $k_{3(1)}{ }^{*}$ and $\theta$; and (c) $k_{3(1)}{ }^{* *}$ and $\tan \theta$ for $B / D=1$.

are slightly smaller than the results using proposed method. The average error between experimental results and proposed method results is about $4.2 \%$. This error occurs due to the soil compaction process for each layer of backfill.

\section{Discussions}

The results show that the modification for $\gamma \mathrm{h}$ is necessary for the HFCCT; the deviation increases as the backfill height increases. On the contrary, for the shallow backfill, the results have little difference regardless of estimation methods used.

The vertical earth pressure may be greater or smaller than $\gamma \mathrm{h}$, which is as shown as Figure 17. The greater deviation between the computed value and $\gamma$ h is highly relevant to the coupling effect of slope angel and $D / B$ ratio. To avoid overestimating and underestimating the vertical earth pressure for the HFCCT in design, the $k_{3}$ is the most significant parameter to modify and reduce the vertical earth pressure.

\section{Conclusion}

The conventional methods for estimating vertical earth pressure are not applicable to the HFCCT. Several influential factors such as shape of CCT's section, stiffness of backfill soil, dimension of CCT, slope angle, and the $D / B$ ratio should be carefully considered in order to more precisely estimate 


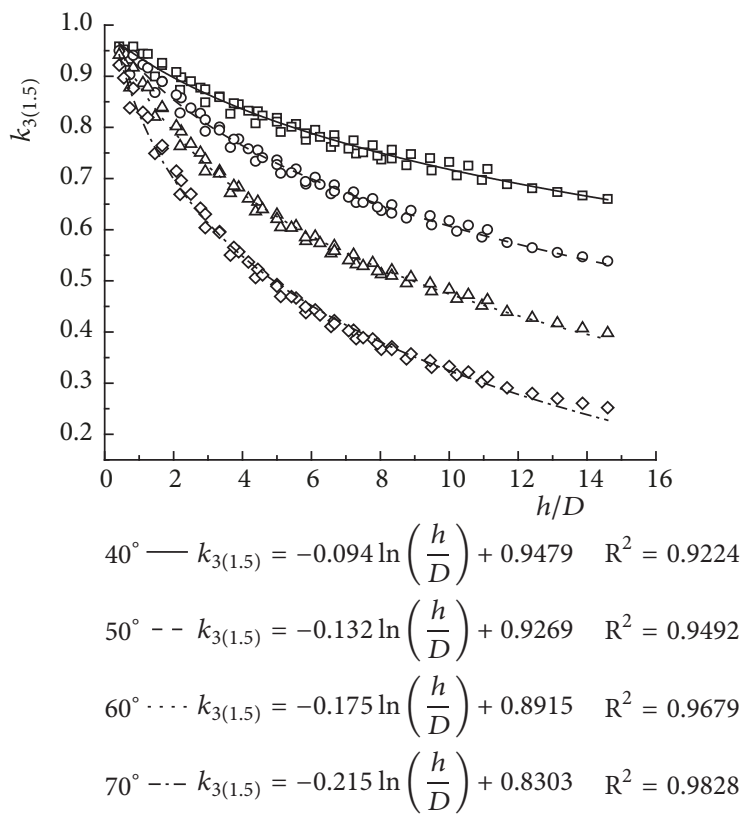

(a)
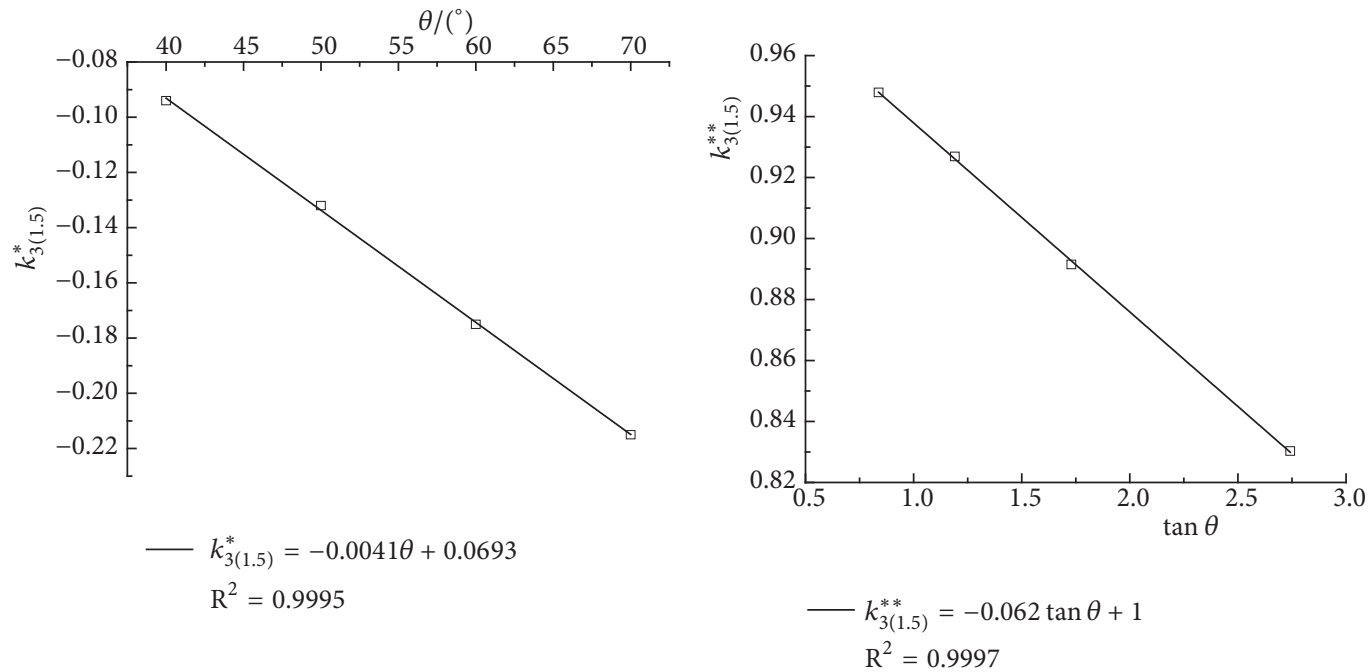

(b)

(c)

Figure 14: Relationship between (a) $k_{3(1.5)}$ and $h / D$; (b) $k_{3(1.5)}{ }^{*}$ and $\theta$; and (c) $k_{3(1.5)}{ }^{* *}$ and $\tan \theta$ for $B / D=1.5$.

the vertical earth pressure on the top of HFCCT. Based on these parametric studies using finite element analysis, the coefficients for modifying the soil column pressure, $\gamma h$, are proposed. The results were verified using both numerical analyses and experiments. Several conclusions can be drawn.

(1) The theory of soil column method is not applicable to the HFCCT. The deviation increases with the height of backfill increasing. Therefore, the estimation of vertical earth pressure must be modified.

(2) Four coefficients are proposed to modify the soil column pressure, $\gamma \mathrm{h}$, using finite element analysis. Four general forms corresponding to these coefficients are $k_{0}$, cross-sectional shape of CCT effect; $k_{1}$, stiffness of backfill effect; $k_{2}$, width of CCT effect; and $k_{3}$, coupling effect of slope angle, $\theta$, and the ratio of $B / D$ effect.

(3) For existing or newly designed HFCCT, the coefficient of $k_{0}$ is 1.0, regardless of cross-sectional shapes; $k_{1}$ is less than 1.0 and can be as low as about 0.8, depending on the height of backfills; $k_{2}$ is a coefficient which is always greater than 1.0. The $k_{2}$ increases with the height of backfills and decreases with the dimension of CCT; $k_{3}$ is equal to or less than 1.0 depending on the coupling effect of slope angle of the valley adjacent to the backfills and the ratio, $B / D$. 


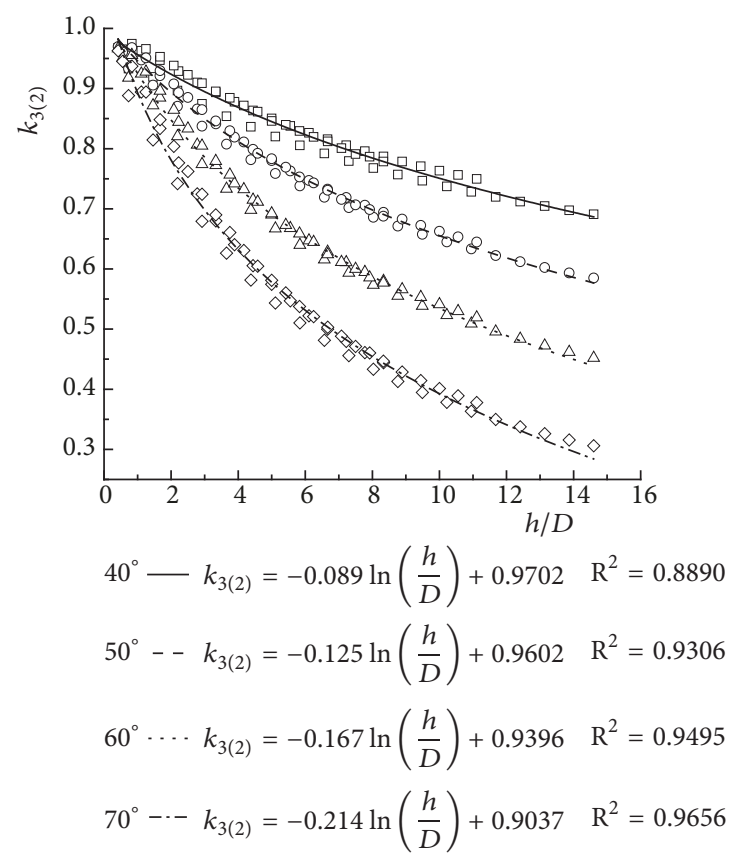

(a)

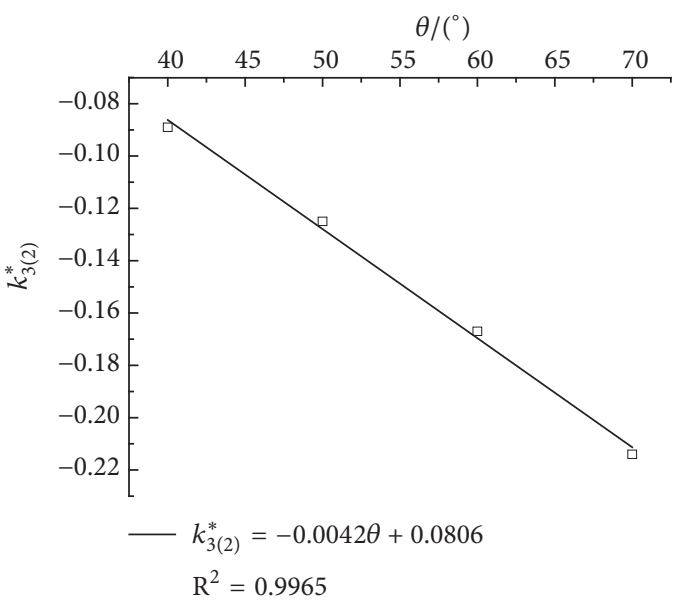

(b)

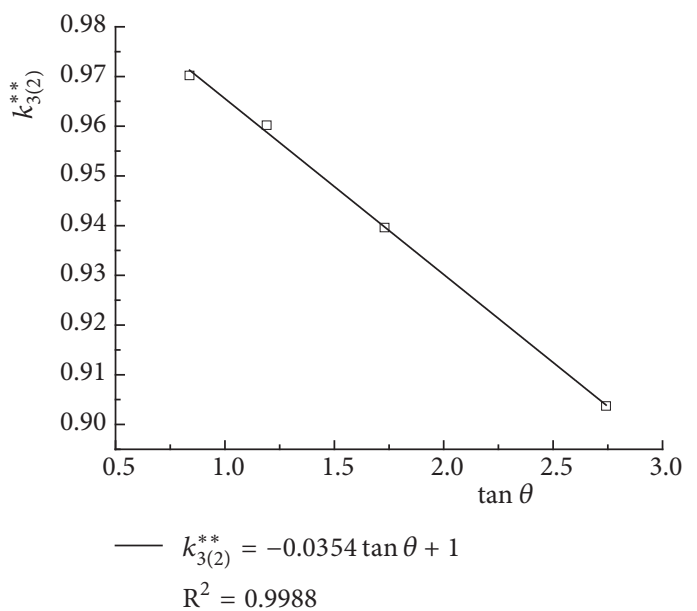

(c)

Figure 15: Relationship between (a) $k_{3(2)}$ and $h / D$; (b) $k_{3(2)}{ }^{*}$ and $\theta$; and (c) $k_{3(2)}{ }^{* *}$ and $\tan \theta$ for $B / D=2$.

(4) For the overall impacts of these coefficients on earth pressure for the HFCCT, the coefficients of $k_{3}$ and $k_{1}$ reduce the vertical earth pressure, the $k_{2}$ will amplify the vertical earth pressure, and $k_{0}$ has little influence on earth pressure. Therefore, to ensure the safety and reduce the vertical earth pressure on the top of HFCCT, proper consideration of the coefficients of $k_{3}$ and $k_{1}$ is necessary before and during the construction process.

\section{Data Availability}

The summarized resulted data used to support the findings of this study are included within the article.

\section{Conflicts of Interest}

The authors declare that they have no conflicts of interest.

\section{Acknowledgments}

This study was supported by the National Science Foundation of China (51668036, 51868041), General Projects of Scientific Research of High School in Gansu (2017A-111), the Program of Changjiang Scholars and Innovative Research Team in University (IRT_15R29), Support Program Funding of Collaborative Innovation Technology Team in Gansu Provincial (2017C-08) and Projects of Excellent Research Team in Lanzhou Jiaotong University (201606), China, 


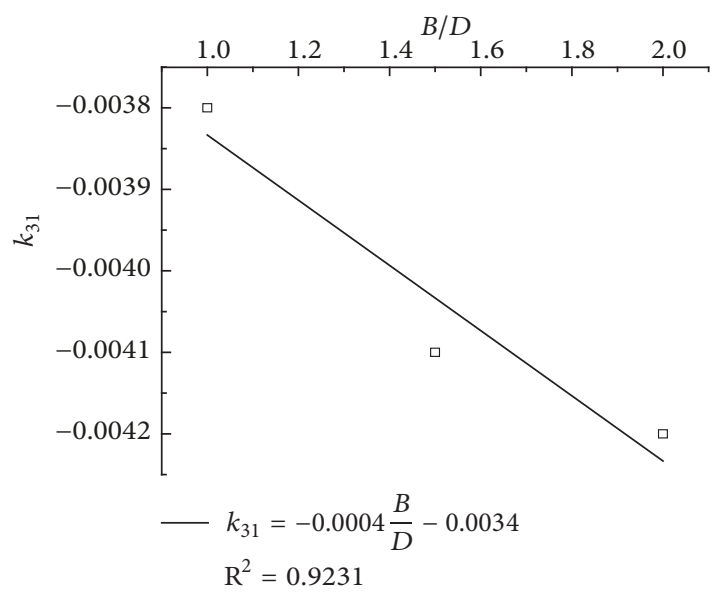

(a)

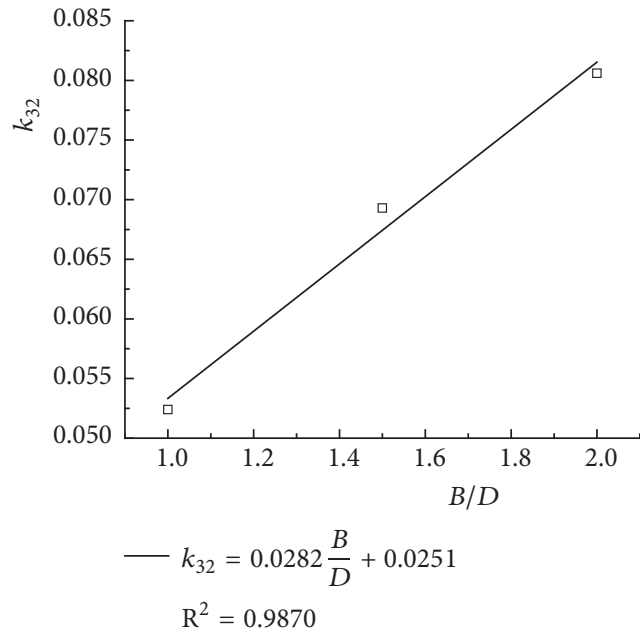

(b)

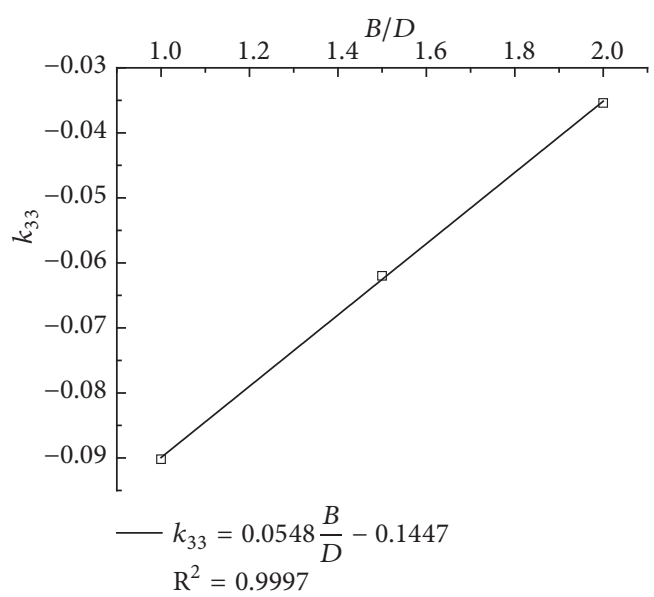

(c)

Figure 16: Relationship between (a) $k_{31}$; (b) $k_{32}{ }^{*}$; and (c) $k_{33}{ }^{* *}$ and $B / D$.

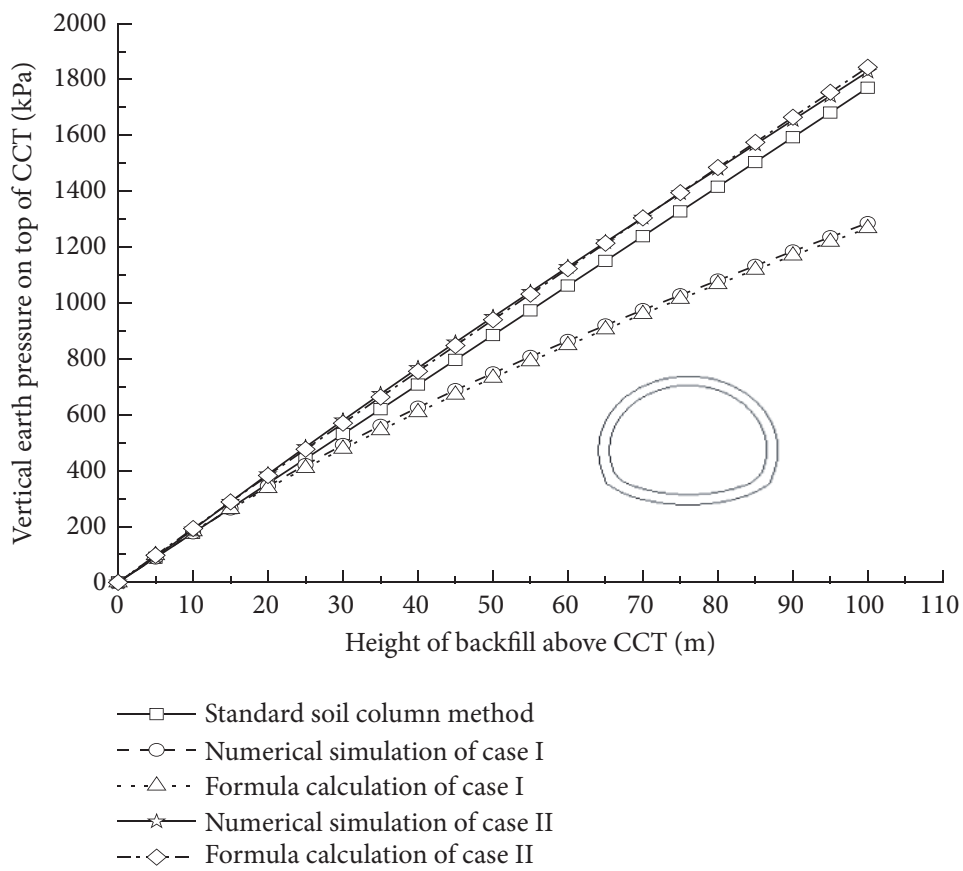

FIGURE 17: Comparisons of vertical earth pressure on the top of CCT versus backfill height using different analysis methods. 


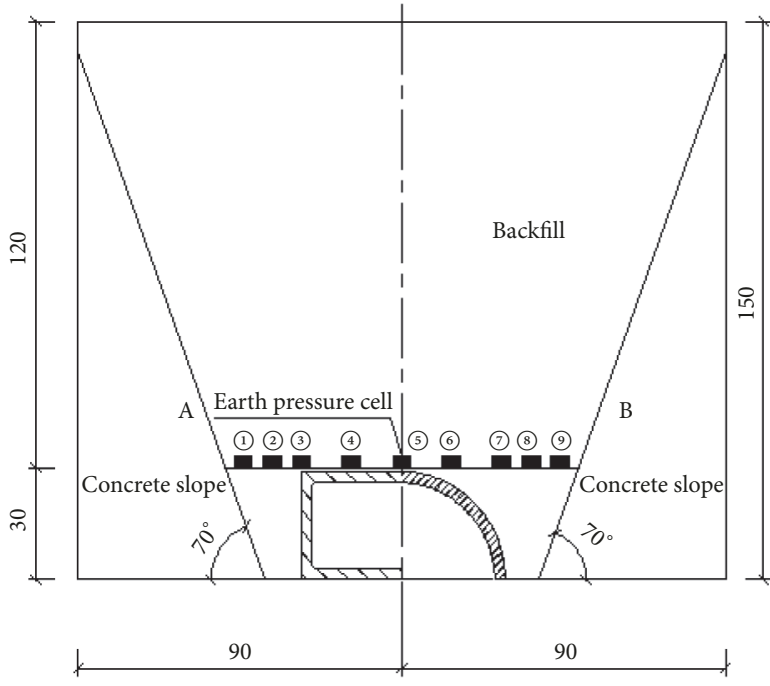

(a)

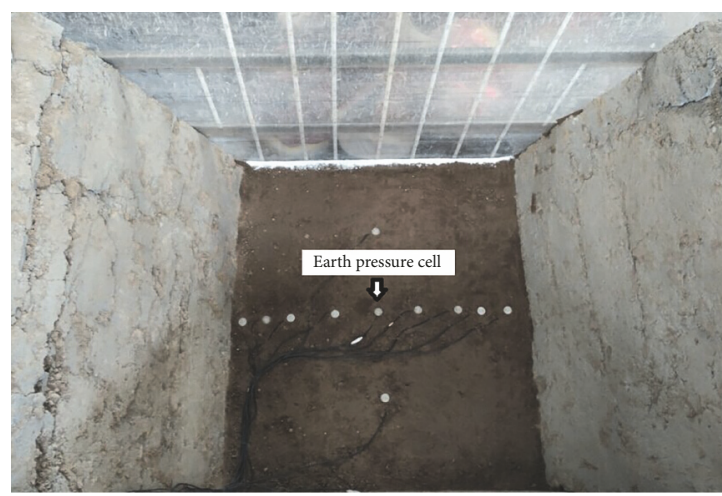

(b)

FIGURE 18: Experimental setup for (a) cross-section illustration of HFCCT apparatus (unit: $\mathrm{cm}$ ) (both rectangular and arched design) and (b) longitudinal and cross-sectional pressure cells on top of CCT.

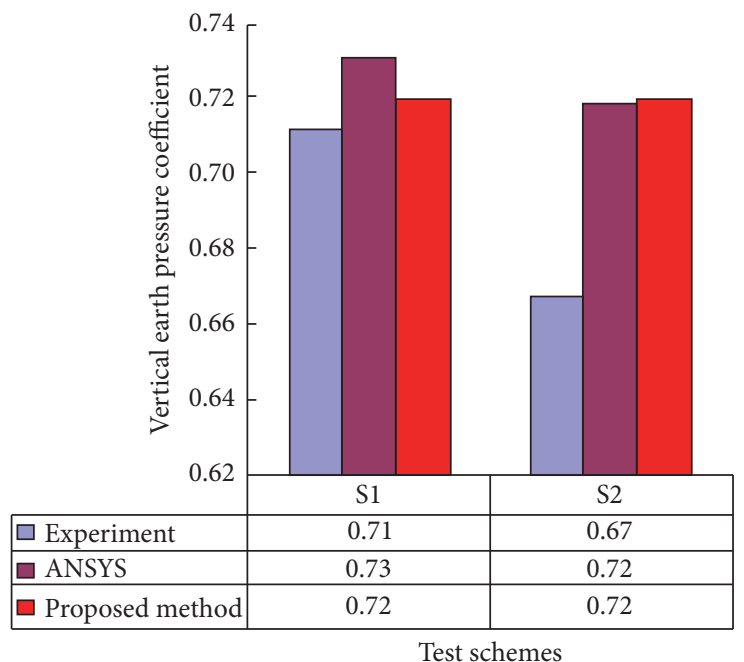

Figure 19: Comparison of vertical earth pressure coefficients on top of CCT for numerical analysis, experimental results, and proposed method.

Energy Geomechanics Laboratory at the University of North Dakota, and Mr. Daniel Brunson at the University of North Dakota.

\section{References}

[1] A. Marston and A. O. Anderson, The Theory of Loads on Pipes in Ditch and Tests of Cement and Clay Drain Tile and Sever Pipe, Iowa Engineering Experiment Station, Ames, Iowa, USA, 1913.

[2] A. Marston, The Theory of External Loads on Closed Conduits in the Light of the Latest Experiments, Iowa Engineering Experiment Station, Ames, IA, USA, 1930.

[3] J. Kang, F. Parker, and C. H. Yoo, "Soil-structure interaction and imperfect trench installations for deeply buried concrete pipes,"
Journal of Geotechnical and Geoenvironmental Engineering, vol. 133, no. 3, pp. 277-285, 2007.

[4] J. Kang, F. Parker, Y. J. Kang, and C. H. Yoo, "Effects of frictional forces acting on sidewalls of buried box culverts," International Journal for Numerical and Analytical Methods in Geomechanics, vol. 32, no. 3, pp. 289-306, 2008.

[5] W. V. Binger, "Discussion to underground conduits-an appraisal of modern research," Proceedings of the American Society of Civil Engineers, vol. 73, pp. 1543-1545, 1947.

[6] M. Z. Yang, Evaluation of factors affecting earth pressures on buried box culverts [Ph.D. thesis], University of Tennessee, Knoxville, Tenn, USA, 2000.

[7] B. G. Chen and L. Sun, "Performance of a reinforced concrete box culvert installed in trapezoidal trenches," Journal of Bridge Engineering, vol. 19, no. 1, pp. 120-130, 2014. 
[8] M. G. Spangler, "Underground conduits-an appraisal of modern research," Transactions of the American Society of Civil Engineers, vol. 113, no. 1, pp. 316-345, 1948.

[9] D. H. Trollope, M. G. Speedie, and I. K. Lee, "Pressure measurements on tullaroop dam culvert," in Proceedings of the 4th Australia-New Zealand Conf. on Soil Mechanics and Foundation Engineering, In stitution of Engineers, pp. 81-92, Barton, ACT, Australia, 1963.

[10] A. D. M. Penman, J. A. Charles, J. K. T. L. Nash, and J. D. Humphreys, "Performance of culvert under winscardam," Geotechnique, vol. 25, no. 4, pp. 713-730, 1975.

[11] A. Q. Gu, "Investigation of the vertical earth pressure on projecting conduit and underground chamber under a high embankment," Chinese Journal of Geotechnical Engineering, vol. 3, no. 1, pp. 3-15, 1981 (Chinese).

[12] A. Dasgupta and B. Sengupta, "Large-scale model test on square box culvert backfilled with sand," Journal of Geotechnical Engineering, vol. 117, no. 1, pp. 156-161, 1991.

[13] R. M. Bennett, S. M. Wood, E. C. Drumm, and N. R. Rainwater, "Vertical loads on concrete box culverts under high embankments," Journal of Bridge Engineering, vol. 10, no. 6, pp. 643-649, 2005.

[14] K. Kim and C. H. Yoo, "Design loading on deeply buried box culverts," Journal of Geotechnical and Geoenvironmental Engineering, vol. 131, no. 1, pp. 20-27, 2005.

[15] J. Vaslestad, T. H. Johansen, and W. Holm, "Load reduction on rigid culverts beneath high fills: long-term behavior," Transportation Research Record, Transportation Research Board, no. 1415, pp. 58-68, 1993.

[16] R. P. McAffee and A. J. Valsangkar, "Field performance, centrifuge testing, and numerical modelling of an induced trench installation," Canadian Geotechnical Journal, vol. 45, no. 1, pp. 85-101, 2008.

[17] B. L. McGuigan and A. J. Valsangkar, "Centrifuge testing and numerical analysis of box culverts installed in induced trenches," Canadian Geotechnical Journal, vol. 47, no. 2, pp. 147$163,2010$.

[18] X.-W. Yang and Y.-X. Zhang, "Study on arch action and earth pressure theory for culverts under high embankment," Journal of Rock Mechanics and Engineering, vol. 24, no. 21, pp. 38873893, 2005 (Chinese).

[19] J.-J. Zheng, B.-G. Chen, and S.-B. Zhang, "Experimental investigation and numerical simulation of nonlinear earth pressure for trench-buried culverts," Chinese Journal of Geotechnical Engineering, vol. 30, no. 12, pp. 1771-1777, 2008 (Chinese).

[20] Y.-G. Li and S.-Y. Zhang, "Experimental and theoretical study on earth pressure on top of rectangular trench-buried culverts," Yantu Lixue/Rock and Soil Mechanics, vol. 29, no. 4, pp. 10811086, 2008 (Chinese).

[21] M. G. Spangler, "A Practical application of the imperfect ditch method of construction," in Proceedings of the Thirty-Seventh Annual Meeting of the Highway Research Board, Highway Research Board, vol. 37, pp. 271-277, Washington, DC, USA, 1958.

[22] N. G. Larsen and J. G. Hendrickson, "A practical method for constructing rigid conduits under high fills," in Proceedings of the 41st Annual Meeting of the Highway Research Board, Highway Research Board, vol. 41, pp. 273-280, Washington, DC, USA, 1962.

[23] R. P. McAffee and A. J. Valsangkar, "Geotechnical properties of compressible materials used for induced trench construction,"
Journal of Testing and Evaluation, vol. 32, no. 2, pp. 143-152, 2004.

[24] R. P. McAffee and A. J. Valsangkar, "Performance of an induced trench installation," Transportation Research Record, Transportation Research Board, vol. 1936, no. 1, pp. 230-237, 2005.

[25] J. A. Sladen and J. M. Oswell, "The induced trench method-a critical review and case history," Canadian Geotechnical Journal, vol. 25, no. 3, pp. 541-549, 1988.

[26] AASHTO, AASHTO Standard Specifications for Highway Bridges, Washington, DC, USA, 2010.

[27] China Communications Construction Company Highway Consultants CO., General Specifications for Design of Highway Bridges and Culverts, Beijing, China, 2015.

[28] China Railway Design Corporation, Code for Design on Railway Bridges and Culvert, Beijing, China, 2017.

[29] China Merchants Chongqing Communications Technology Research \& Design Institute CO., Code for Design of Road Tunnel, Beijing, China, 2004.

[30] China Railway Eryuan Engineering Group CO., Code for Design of Railway Tunnel, Beijing, China, 2017.

[31] L. S. Luo and P. Zhang, "Preliminary study on load of high fill open cut tunnel," High Speed Railway Technology, vol. 5, no. 3, pp. 90-93, 2014 (Chinese).

[32] S. Li, L. Ma, Q. C. Wang, J. X. Li, W. W. Li, and Y. J. Zhang, "Calculation method and influencing factors for earth pressure of high fill open cut tunnel," China Railway Science, vol. 37, no. 5, pp. 41-49, 2016 (Chinese).

[33] A. N. Dancygier, Y. S. Karinski, and A. Chacha, "A model to assess the response of an arched roof of a lined tunnel," Tunnelling and Underground Space Technology, vol. 56, pp. 211225, 2016. 


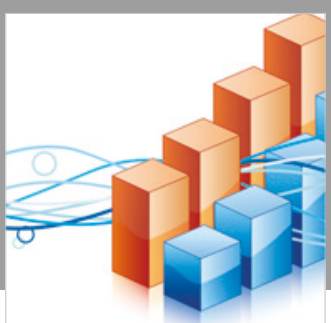

Advances in

Operations Research

\section{-n-m}
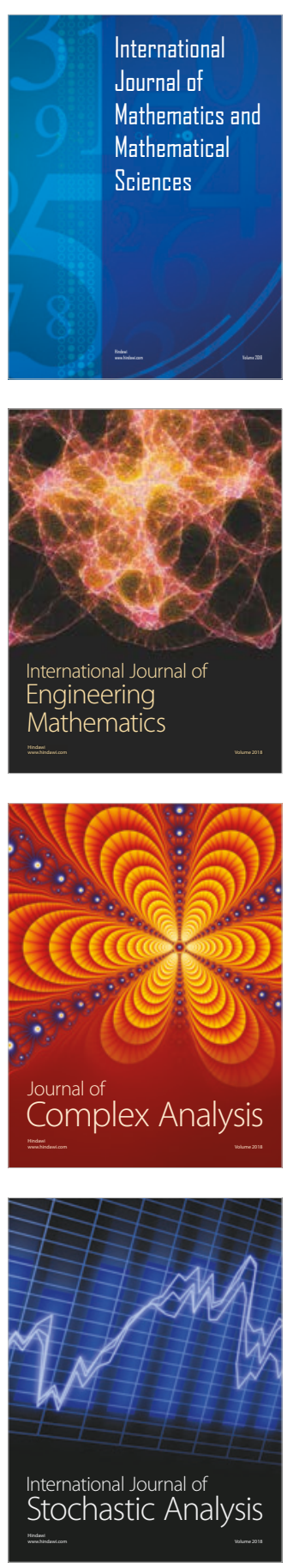
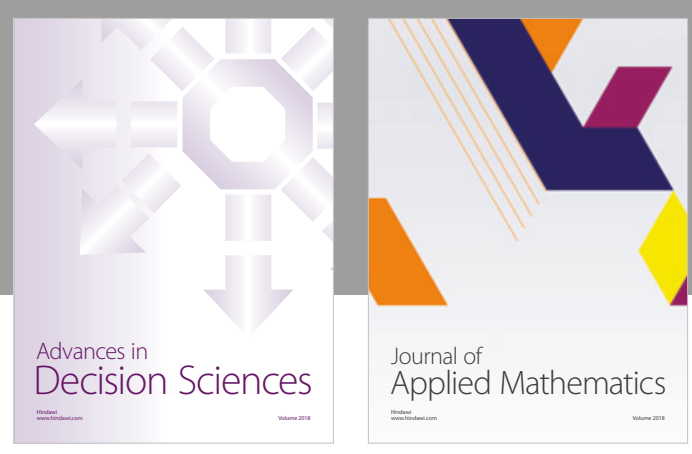

Journal of

Applied Mathematics
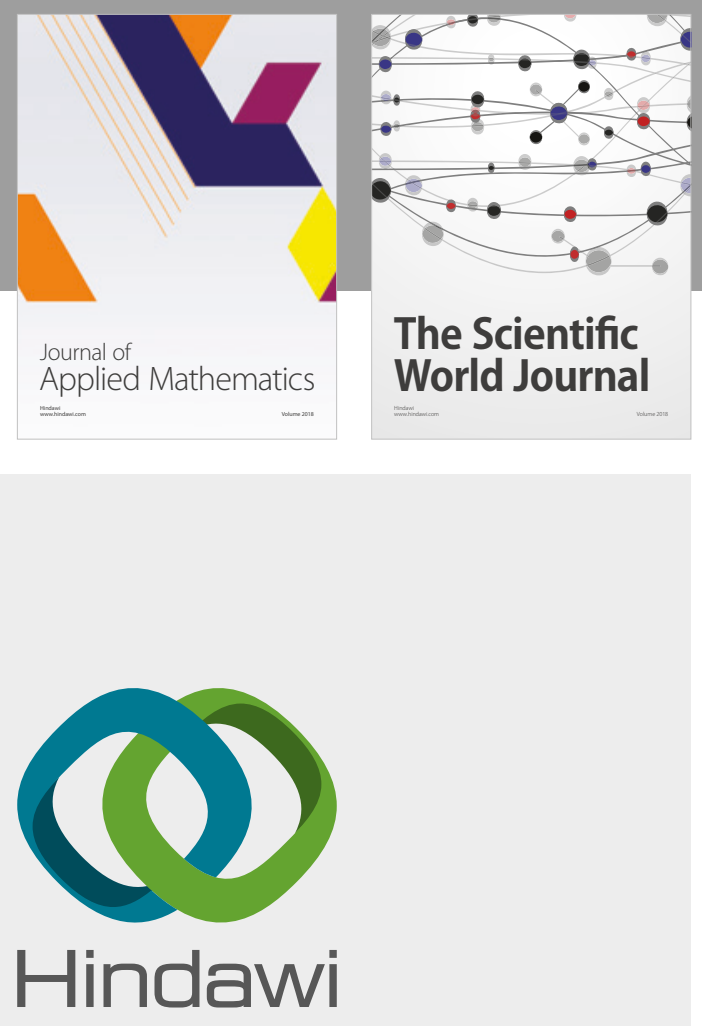

Submit your manuscripts at

www.hindawi.com

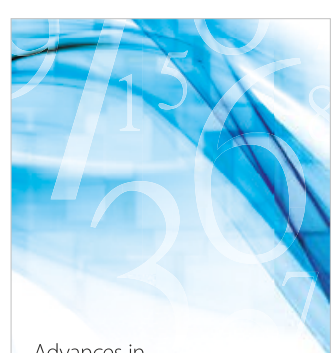

Advances in
Numerical Analysis
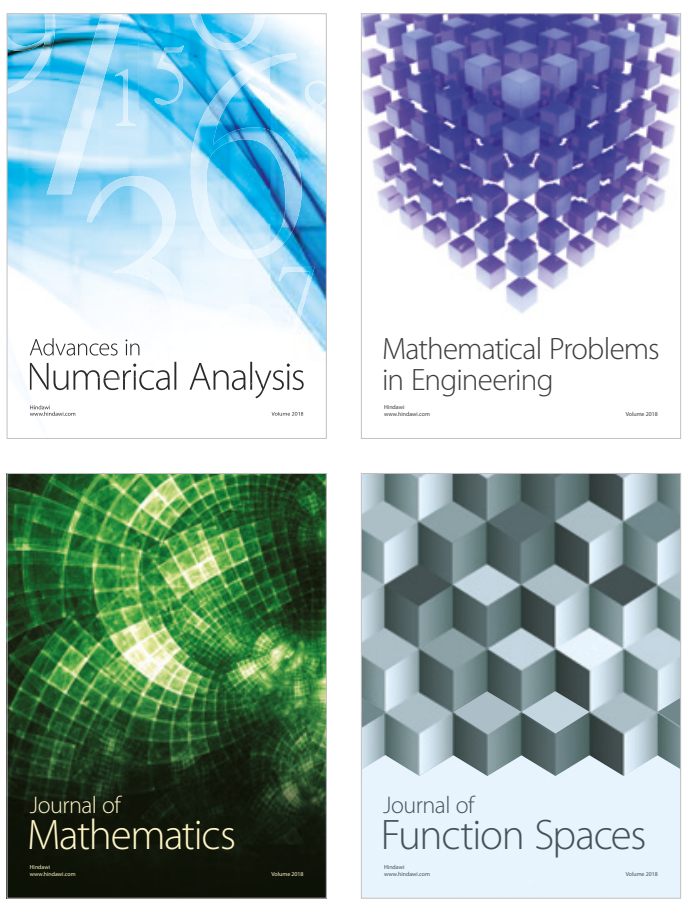

Mathematical Problems in Engineering

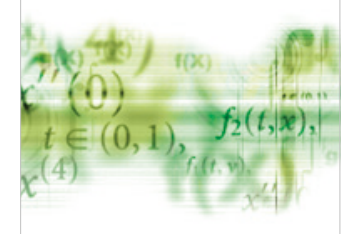

International Journal of

Differential Equations

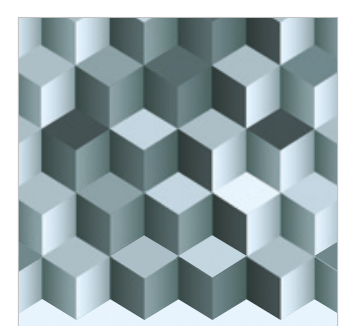

Journal of

Function Spaces

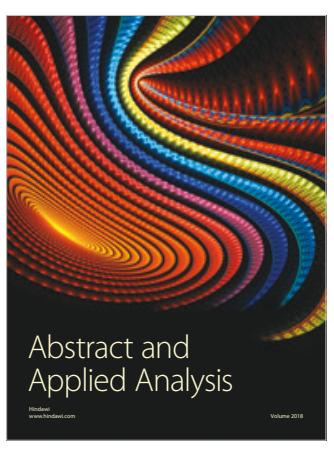

The Scientific

World Journal

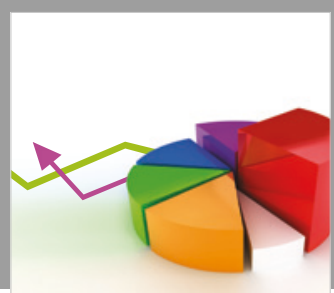

Journal of

Probability and Statistics
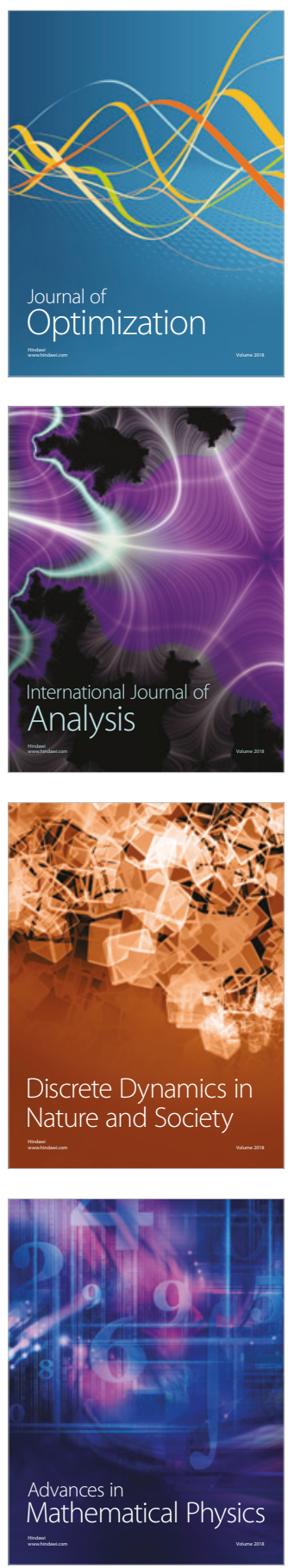